\title{
Surgical management of pediatric inguinal hernia: A systematic review and guideline from the
}

\section{European Pediatric Surgeons' Association Evidence- and Guideline Committee.}

Francesco Morini, MD' ${ }^{1}$, Kelly M.A. Dreuning, $\mathrm{MD}^{2}$, Maarten J.H. Janssen Lok, MD³, Tomas Wester, $\mathrm{MD}, \mathrm{PhD}^{4}$, Joep P.M. Derikx, MD, PhD², Florian Friedmacher, $\mathrm{MD}, \mathrm{MSc}, \mathrm{PhD}^{5,6}$, Hiromu Miyake, $\mathrm{MD}^{7}$,

Haitao Zhu, MD, PhD ${ }^{3,8}$, Luca Pio, $\mathrm{MD}^{9}$, Martin Lacher, MD, PhD ${ }^{10}$, Stefania Sgró, MD ${ }^{11}$, Augusto Zani, MD, PhD, FACS, FAAP ${ }^{3,12}$, Simon Eaton, PhD ${ }^{13}$, L.W. Ernest van Heurn, MD, PhD², Agostino Pierro,

OBE, MD, FRCS(Engl), FRCS(Ed), FAAP

\footnotetext{
${ }^{1}$ Department of Medical and Surgical Neonatology, Ospedale Pediatrico Bambino Gesù, IRCCS, Rome, Italy

2 Department of Pediatric Surgery, Emma Children's Hospital, Amsterdam UMC, University of Amsterdam \& Vrije Universiteit Amsterdam, Amsterdam, The Netherlands

${ }^{3}$ Division of General and Thoracic Surgery, The Hospital for Sick Children, University of Toronto, Toronto, ON, Canada

${ }^{4}$ Department of Pediatric Surgery, Karolinska University Hospital, Karolinska Institutet, Stockholm, Sweden

${ }^{5}$ Department of Pediatric Surgery, The Royal London Hospital, London, United Kingdom

${ }^{6}$ Department of Pediatric Surgery, University Hospital Frankfurt, Goethe University Frankfurt, Frankfurt/Main, Germany

${ }^{7}$ Department of Pediatric Surgery, Shizuoka Children's Hospital, Shizuoka, Japan

${ }^{8}$ Department of Pediatric Surgery, Children's Hospital of Fudan University, Shanghai, China

${ }^{9}$ Department of Pediatric Surgery and Urology, Hôpital Universitaire Robert-Debré, University of Paris, Paris, France

${ }^{10}$ Department of Pediatric Surgery, University of Leipzig, Leipzig, Germany

${ }^{11}$ Department of Anesthesiology, Ospedale Pediatrico Bambino Gesù, IRCCS, Rome, Italy

${ }^{12}$ Department of Surgery, University of Toronto, Toronto, ON, Canada

${ }^{13}$ Developmental Biology and Cancer Programme, UCL Great Ormond Street Institute of Child Health, London, United Kingdom
}

\section{Corresponding author:}

Francesco Morini, MD

Department of Medical and Surgical Neonatology, Ospedale Pediatrico Bambino Gesù, IRCCS, Rome, Italy. E-mail: francesco.morini@obpg.net, Tel: +390668592523 


\section{Abstract}

Introduction

Inguinal hernia repair represents the most common operation in infancy; however, consensus about the optimal management, from surgical timing to the best technique is lacking. Hence, recommendations for clinical practice are needed. This study assesses the available evidence and compiles recommendations on pediatric inguinal hernia.

\section{Materials and Methods}

The European Pediatric Surgeons' Association Evidence- and Guideline Committee addressed six questions on pediatric inguinal hernia repair with the following topics (1) open versus laparoscopic and (2) extra-peritoneal versus trans-peritoneal repair, (3) contralateral exploration, (4) surgical timing and (5) anesthesia technique in preterm infants and (6) operation urgency in girls with irreducible ovarian hernia. Systematic literature searches were performed querying PubMed, MEDLINE, Embase (Ovid) and The Cochrane Library. Reviews and meta-analyses were conducted according to the PRISMA statement.

\section{Results}

Seventy-two out of 5173 articles were included, 27 in the meta-analyses. Laparoscopic repair shortens operation time compared to open repair. In preterm infants, hernia repair after NICU/hospital discharge is associated with less respiratory difficulties and recurrences, regional anesthesia decreases postoperative apnea and pain. The review regarding operation urgency for irreducible ovarian hernia gained insufficient evidence of low quality.

\section{Conclusions}

Laparoscopic repair may be beneficial for children with inguinal hernia and preterm infants may benefit using regional anesthesia and postponing surgery. However, no definite superiority was found and 
66

67

68

69

70

71

72

73

74

75

76

77

78

79

80

81

82

83

84

85

86

87

88 82 87

available evidence was of moderate to low quality. Evidence for other topics was less conclusive. For the optimal management of inguinal hernia repair a tailored approach is recommended considering the local facilities, sources and the expertise of the medical team involved.

Keywords: Hernia, Inguinal; Laparoscopy; Anesthesia, General; Child; Ovary.

(1)

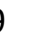

0

1

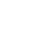

3

84 85 86 88 


\section{Introduction}

Inguinal hernia is one of the most common pediatric surgical disorders, characterized by protrusion of intra-abdominal contents, e.g. omentum, intestines or ovary, through the patent processus vaginalis in the inguinal region. The incidence of inguinal hernia during childhood is estimated between 8 to 50 of every 1000 live births, rising to almost $20 \%$ in premature or very low birth weight infants ${ }^{1,2}$. The risk for incarceration in term and preterm children is reported to be $12 \%$ and $39 \%$, respectively ${ }^{3}$. In some children, inguinal hernia may be asymptomatic; however surgical repair is always necessary because of the risk of incarceration. Over the past decade, there is increasing evidence regarding the best treatment options for pediatric inguinal hernia. Nevertheless, there are still controversies about the optimal timing for hernia repair in premature infants and girls with irreducible ovarian hernia, whether the operation should be done as an open repair or laparoscopically, and whether contralateral exploration should be performed at the time of unilateral hernia repair or not. In adults, several international guidelines have already been proposed for the treatment of inguinal hernia ${ }^{4,5}$. Although pediatric surgeons will inevitably face numerous cases of inguinal hernia in their professional careers, there are no (international) guidelines for the management of inguinal hernias in infants and children. The aim of this systematic review is to collect all currently available evidence and to compile recommendations for future treatment of inguinal hernia in the pediatric population.

\section{Materials and Methods}

Research questions

The members of the European Pediatric Surgeons' Association (EUPSA) Evidence Based Practice Committee drafted and iteratively refined six questions regarding the management of pediatric inguinal hernia, including primary and secondary outcomes for each question. These questions guided this systematic review and Evidence-Based guideline (Table 1).

1. Is laparoscopic inguinal hernia repair associated with better outcome compared to open repair? 
2. Which laparoscopic technique is associated with better outcome: the extra-peritoneal approach or trans-peritoneal approach?

\section{Protocol and registration} required for execution of this review.

\section{Search strategy}

A comprehensive literature search was conducted in March 2019 using PubMed, MEDLINE, Embase

(Ovid) and The Cochrane Library databases using Medical Subject Headings (MeSH) and text words that were specific to each research question (Appendix 1. Search strategy). Reference lists of included articles were screened for identification of additional studies. Selection of studies was restricted to full-text articles available in English, without any limits to the year of publication. 
For each question, two review authors independently screened and reviewed all articles that were

identified for their specific research question based on title, key words and abstract, and full-text for final selection. Randomized controlled trials, case-control studies, case-series and retrospective studies were considered eligible for inclusion. Review articles, letters to the editor, conference abstracts, poster presentations and case reports were excluded. If the full text of articles was not available from one of the libraries, it was retrieved by contacting the authors. Any discrepancies in the selection process were resolved by second joint review of the literature to reach mutual consensus or by consulting a third independent review author if necessary.

\section{Quality assessment}

Risk of bias assessment of the included studies was performed using Risk of Bias 2.0 (RoB 2.0) for randomized clinical trials, as recommended by members of the Cochrane collaboration. RoB 2.0 assessed the bias of studies in the following domains: randomization process, deviations from intended interventions, missing data, measurement of the outcome and selection of the reported results. Each domain was scored as "low risk", "some concerns" or "high risk" and the overall risk of bias was determined. In addition, for non-randomized studies, Risk of Bias in Non-Randomized Studies of Interventions (ROBINS-I) was used. ROBINS-I assessed the bias of studies in the following domains: confounding, selection of participants into the study, classification of interventions, deviations from intended interventions, missing data, measurement of outcomes and selection of the reported result. Each of the domains was scored as "low", "moderate", "serious", "critical risk" or "NI, no information" and an overall risk of bias was determined.

\section{Data extraction and review process}

Two review authors systematically extracted all relevant study information and patient characteristics pertinent to their review question from studies included in their part of the review. Primary and secondary outcome measures for each review question are presented in Table 1. Missing data were 
calculated or retrieved from the author(s) if necessary. The Oxford Centre for Evidence-Based Medicine

Classification of levels of evidence and grades of recommendation was used to assess the level of evidence of the included studies and grade the strength of the recommendations (Table 2) ${ }^{7}$. In June 2019 , the results of this systematic review together with the corresponding recommendations were presented at the EUPSA annual conference in Belgrade, Serbia, and subsequently opened for discussion.

\section{Statistical analysis}

Statistical analyses were performed using Review Manager (RevMan), version 5.3 (The Nordic Cochrane Centre, The Cochrane Collaboration, Copenhagen, 2014) and MedCalc, version 18.5. Weighted mean differences (WMD) and pooled estimates of proportion (\%) or odds ratios (OR) with their corresponding $95 \%$ confidence intervals ( $\mathrm{Cl}$ ) were calculated for the analysis of continuous and dichotomous variables, respectively. Meta-analyses were performed using a random-effects model according to the Mantel-Haenszel method. Heterogeneity between the included studies was assessed using the inconsistency $\left(I^{2}\right)$ score and was considered substantial if above $50 \%$.

\section{$\underline{\text { Results }}$}

\section{Search strategy}

Literature search and manual reference analysis showed 5173 articles after duplicates were removed. After the initial screening and exclusion of 5016 articles, 157 full-text articles were assessed for eligibility. In total, 72 articles were included in the qualitative synthesis of the six review questions

(Figure 1). Twenty-seven articles were finally included in the meta-analyses.

\section{Quality assessment}

Quality assessment was performed on all different outcomes using the Cochrane RoB 2.0 tool for randomized clinical trials and the ROBINS-I tool for non-randomized studies of interventions (Appendix 

meta-analysis for review question 1 and 2 was considered low. Overall risk of bias for randomized studies included for review question 5 was considered high, except for one study. Risk of bias assessment using the ROBINS-I tool for non-randomized studies that were included for review questions 2, 3, 4 and 6 showed that there was a serious or critical risk of bias concerning several domains.

Question 1. Is laparoscopic hernia repair associated with better outcome compared to open repair? Recommendation (Level 1 evidence; Grade B): Based on the currently available evidence there is no definite superiority of either the laparoscopic or open treatment strategy regarding perioperative (i.e. spermatic cord/vessel injury, ovarian lesion and bleeding) and postoperative (i.e. hematoma, edema, hydrocele, wound infection and testicular atrophy) complications, recurrence rate and development of metachronous contralateral inguinal hernia (MCIH). Laparoscopic inguinal hernia repair might be advantageous in children with bilateral inguinal hernia in terms of reduced operation time.

\section{Background}

Hernia repair can be performed either with the traditional open, or the increasingly used laparoscopic approach. Laparoscopic hernia repair is believed to result in shorter operation time for children with bilateral inguinal hernia and less postoperative complications compared to open hernia repair ${ }^{8,9}$. Thereby, laparoscopic repair allows for contralateral exploration and simultaneous repair of the processus vaginalis if it remains to be patent. However, no differences in long-term outcome after laparoscopic repair of a contralateral patent processus vaginalis could yet be identified ${ }^{9}$.

Eight randomized controlled trials that compared laparoscopic ( $n=375$ patients) to open pediatric hernia repair ( $n=375$ patients) could be included in the meta-analysis ${ }^{10-17}$. Patients' age at the time of 
surgery and mean follow-up time in the included studies ranged from 0 to 18 years and 24 hours to 30 months, respectively (Appendix 3).

There were no differences between the complication and recurrence rates. Perioperative complications including injury to spermatic cord or spermatic vessels, ovarian lesion or bleeding (OR $3.16[95 \% \mathrm{Cl} 0.34$ to 29.60$\left.], l^{2}=0 \%, \mathrm{p}=0.31\right)^{10,12,15,16}$ and postoperative complications including hematoma, edema, hydrocele, wound infection and testicular atrophy (OR 0.37 [95\% $\mathrm{Cl} 0.10$ to 1.32 ], $\left.I^{2}=55 \%, p=0.13\right)^{10-12,14-16,18}$ between laparoscopic and open hernia repair were similar. Recurrence rates after laparoscopic and open hernia repair were reported to be $1.1 \%$ and $1.2 \%$, respectively (OR 0.88 [95\% Cl 0.20 to 3.88 ], $\left.I^{2}=0 \%, \mathrm{p}=0.87\right)^{10-12,14-16,18}$.

This meta-analysis demonstrated no differences regarding development of $\mathrm{MClH}$ after laparoscopic versus open hernia repair (OR $0.28[95 \% \mathrm{Cl} 0.04$ to 1.86$\left.], l^{2}=52 \%, p=0.19\right)^{11,14,15,18}$. Unilateral operation time (in minutes)(WMD $0.62[95 \% \mathrm{Cl}-5.70$ to 6.95$\left.], I^{2}=97 \%, \mathrm{p}=0.85\right)^{11-16,18}$, length of hospital stay (in hours)(WMD 0.74 [95\% $\mathrm{Cl}-0.38$ to 1.87 ], $\left.I^{2}=59 \%, \mathrm{p}=0.20\right)^{11,12,14,16,18}$ and time to full recovery (in hours)(WMD $2.05[95 \% \mathrm{Cl}-11.13$ to 15.23$\left.], I^{2}=67 \%, p=0.76\right)^{10-12,14}$ were also not different between the groups. Bilateral operation time (in minutes) was shown to be reduced after laparoscopic repair (WMD -7.19 [95\% Cl-10.04 to -4.34$], l^{2}=73 \%, p<0.001$ )(Table 3 and Appendix 4$)^{10-12,16,18}$.

\section{Discussion and summary}

The results of this meta-analysis on open versus laparoscopic hernia repair indicates that the laparoscopic approach results in shorter operation time for children with bilateral hernia compared to open inguinal hernia repair. Complication and recurrence rates were not different between both techniques. Additionally, it has recently been demonstrated that in particular the laparoscopic hernia repair technique with extracorporeal suturing is likely to be associated with less complications and shorter operation time compared to intracorporeal suturing ${ }^{19}$. The recurrence rate was potentially found to be higher after laparoscopic repair ${ }^{20}$, whereas two recent meta-analyses could not demonstrate any differences between open and laparoscopic repair with respect to recurrence 
rates $^{8,21}$. It is believed that laparoscopic surgery with simultaneous repair of the contralateral patent processus might be advantageous to prevent development of $\mathrm{MCIH}$, although based on the currently available evidence no difference in $\mathrm{MCIH}$ development could be demonstrated. Still, there is great variety among the laparoscopic techniques that are currently used for repair of inguinal hernias in children and long-term follow-up results are lacking. Therefore, no definite recommendation on the superiority of either the laparoscopic or open treatment strategy can be made.

250

Question 2. Which laparoscopic technique is associated with better outcome: the extra-peritoneal approach or trans-peritoneal approach?

Recommendation (Level 2 evidence; Grade B): Based on the currently available evidence there is no definite superiority for either the laparoscopic extra-peritoneal or trans-peritoneal approach regarding the occurrence of intraoperative (i.e. vessel injury and conversion to open surgery) or postoperative (i.e. hydrocele, wound infection and testicular atrophy) complications and recurrence rate. In comparison with the trans-peritoneal approach, the laparoscopic (unilateral and bilateral) extra-peritoneal approach may result in reduced operation time in children with inguinal hernia.

Background

Minimally invasive surgery for the repair of pediatric inguinal hernia is often performed, and innovations in laparoscopic hernia techniques evolve alongside its increasing popularity. Speck and Smith previously described the evolution of laparoscopic hernia repair techniques and demonstrated the different methods of minimally invasive closure of pediatric inguinal hernias for the Society of American Gastrointestinal and Endoscopic Surgeons ${ }^{22}$. The techniques can be roughly categorized by the number of ports and the suturing technique that is used to close the internal inguinal ring: extracorporeal suturing through the pre-peritoneal plane or intra-corporeal suturing through the transperitoneal approach. Compared to the open technique, laparoscopic extracorporeal suturing is 
considered to result in fewer complications and shorter unilateral operation time, whereas intracorporeal suturing potentially shortens the time interval between surgery and discharge ${ }^{21}$.

\section{Results}

Shalaby et al. directly compared the extra-peritoneal approach ( $n=75$ patients) to the trans-peritoneal approach ( $n=75$ patients) in a randomized trial and showed that there were no differences between the study groups in postoperative development of hydrocele $(2.7 \%$ versus $4 \%)$ or recurrence rate $(1.3 \%$ versus $4 \%, p=0.61)^{23}$. Intraoperative injury to the spermatic vessels and conversion to the open approach were not reported in either study group. None of the patients developed a postoperative wound infection or testicular atrophy. Mean (SD) duration (in minutes) of bilateral hernia repair was shorter in patients who underwent extra-peritoneal hernia repair compared to trans-peritoneal repair $(11.4 \pm 2.7$ versus $21.9 \pm 7.2, p<0.001)$

Three retrospective cohort studies including 833 patients compared the extra-peritoneal and trans-peritoneal approach and were included in the meta-analysis for the second review question (Appendix 3$)^{24-27}$. No difference was found between the extra-peritoneal and trans-peritoneal approach in recurrence rate ( $\mathrm{OR} 1.22[95 \% \mathrm{Cl} 0.33$ to 4.47$\left.], I^{2}=0 \%, \mathrm{p}=0.77\right)$. Both unilateral (WMD -9.84 [95\% $\mathrm{Cl}-16.33$ to -3.03 ], $\left.I^{2}=97 \%, \mathrm{p}=0.005\right)^{24-26}$ and bilateral (WMD -13.54 [95\% $\mathrm{Cl}-16.08$ to -11.01 ], $\left.I^{2}=54 \% \mathrm{p}<0.001\right)^{24-27}$ operation times were shorter in patients who underwent extra-peritoneal hernia repair. Conversion to open surgery (OR $2.88[95 \% \mathrm{Cl} 0.29$ to 28.28$\left.], l^{2}=0 \%, \mathrm{p}=0.36\right)^{24-27}$, intra-operative vessel injury (OR 0.55 [95\% $\mathrm{Cl} 0.09$ to 3.38 ], $I^{2}=41 \%, \mathrm{p}=0.52$ ), and postoperative complications including wound infection (OR 3.29 [95\% $\mathrm{Cl} 0.17$ to 64.65], $I^{2}=\mathrm{NA}, \mathrm{p}=0.43$ )[MJL1][MF2][KD3], hydrocele (OR 1.04 [95\% $\mathrm{Cl} 0.32$ to 3.30$\left.], l^{2}=0 \%, \mathrm{p}=0.95\right)$, and testicular atrophy (OR $0.15[95 \% \mathrm{Cl} 0.01$ to 3.76$], l^{2}=\mathrm{NA}$, $\mathrm{p}=0.25)$ did not differ ${ }^{24-27}$ (Table 3 and Appendix 4).

\section{Discussion and summary}


In 2009, the International Pediatric Endosurgery Group Evidence-Based Review Committee was not

295 yet able to make clear recommendations on a specific method for minimally invasive hernia repair in

296 children since level 1a evidence comparing different laparoscopic techniques was lacking ${ }^{9}$. Based on

297 low-quality evidence from retrospective studies that were included in this meta-analysis, the extra-

298 peritoneal approach is believed to reduce the operation time of both unilateral and bilateral

299 laparoscopic hernia repair in children. Moderate quality evidence from a single randomized controlled

300 trial considers only bilateral inguinal hernia repair in children to be shorter using the extra-peritoneal

301 technique. Additional high-level evidence is required before definite conclusions can be drawn.

302

Question 3. Should contralateral inguinal exploration be performed at the time of open unilateral

304

305

306

307

308

309

310

311

312

313

314

315

\section{inguinal hernia repair?}

Recommendation (Level 2 and 3 evidence): Since high-level evidence comparing contralateral exploration to unilateral repair without contralateral exploration is lacking and there is extensive heterogeneity among the currently available evidence, no clear recommendation can be made.

\section{Background}

In children who present with unilateral inguinal hernia, a second contralateral hernia (i.e. metachronous inguinal hernia, $\mathrm{MCIH}$ ) occurs in $10-15 \%$ after unilateral repair ${ }^{28}$. No definite risk factors could be identified for $\mathrm{MClH}$ development and accurate diagnostic modalities (e.g. preoperative ultrasonography) to detect or predict development of $\mathrm{MCIH}$ are lacking ${ }^{29,30}$. For several decades, routine exploration of the contralateral groin during unilateral surgery and simultaneous repair of an existing contralateral patent processus vaginalis (CPPV) has been believed to potentially prevent development of $\mathrm{MCIH}$. However, as not all CPPVs necessarily develop into clinically relevant $\mathrm{MCIH}$, and contralateral exploration also increases the risk for (potentially unnecessary) operative complications, controversy still exists whether to perform contralateral exploration or not ${ }^{28,31-33}$. This is especially 
intriguing in light of a recent warning on the potentially harmful impact of repeated anesthesia on the child's brain, that was recently released by the US Food and Drug Administration ${ }^{34}$.

\section{Results}

Twenty-four studies retrospectively evaluated the use of contralateral exploration of which 23 studies ( $n=9063$ patients) could be included in the data-analysis ${ }^{35-58}$. Age at surgical repair and duration of follow-up ranged from 1 week to 16 years and 3 months to 10 years, respectively (Appendix 3).

Twenty-three studies ( $n=5726$ patients) performed contralateral exploration and assessed its results. Pooled estimate of positive contralateral exploration rates showed that the processus vaginalis was found to be patent in $63.49 \%$ ([95\% Cl 56.88 to 69.87$\left.], I^{2}=95.76 \%\right)^{36,37,39-59}$. Pooled estimates of eleven studies ( $n=3008$ patients) evaluating the results of patients who did not undergo contralateral exploration, showed that $\mathrm{MClH}$ developed in $8.4 \%$ ([95\% Cl 5.48 to 11.90$], I^{2}=85.88 \%$ )(Table $4)^{36,37,39,40,42,43,49,50,57-59}$.

Complications including testicular atrophy, hydrocele, hematoma, wound infection, apnea and recurrence were described by thirteen studies and reported to be found in $1.97 \%$ ([95\% $\mathrm{Cl} 0.98$ to 3.29 ; $I^{2}=81.03$ ) of 3230 patients $36,37,40-42,44,48,50,51,53,55-57$. Six studies ( $n=1096$ patients) reported that contralateral exploration increases the total anesthesia time by on average 15-20 minutes $40,41,45,47,51,55$. Mean values with the corresponding standard deviations of both unilateral repair and unilateral repair with contralateral exploration were not reported. Furthermore, in patients who underwent unilateral hernia repair and subsequent second surgery following development of $\mathrm{MCIH}$, the duration of surgery was not reported.

\section{Discussion and summary}

Based on the results of this review, the contralateral processus vaginalis is found to be patent in $63.5 \%$ of the children with unilateral inguinal hernia, whereas on the contrary only $8.4 \%$ of the children who underwent unilateral hernia repair without contralateral exploration actually develop a $\mathrm{MCIH}$. The 
average complication rate of contralateral exploration is $1.97 \%$, although no study directly compared the complications of contralateral exploration to the complications of unilateral hernia repair and subsequent development of $\mathrm{MClH}$. Contralateral exploration appears to increase anesthesia time by 15-20 minutes; however, unilateral hernia repair with subsequent second anesthesia and surgery if $\mathrm{MClH}$ develops, will probably increase anesthesia time even more.

In 2011, Nataraja et al. performed a systematic review on the evidence for routine contralateral exploration during open hernia repair and reported an overall risk for $\mathrm{MClH}$ development of $5.76 \%(95 \% \mathrm{Cl} 5.55$ to 5.97$)$. They also found that patients younger than six months $(12.4 \%)$ and patients with an initial left-sided inguinal hernia (12.1\%) were more likely to develop a $\mathrm{MCIH}^{28}$. Laparoscopic evaluation of the contralateral processus during open or laparoscopic hernia repair is increasingly performed as the laparoscopic technique or the use of a laparoscope through the ipsilateral hernia sac allows clear visualization of the contralateral ring. Chong et al. recently assessed the long term follow-up results of open ( $n=1156$ patients) and laparoscopic $(n=541)$ hernia repair in children and found that the use of laparoscopy to visualize the contralateral side resulted in a significantly lower rate of $\mathrm{MClH}$ repair $(3.8 \% \text { versus } 0.8 \%)^{60}$. This corresponds to the results of a recent systematic review by Muensterer et al. who found that a CPPV was concomitantly found during laparoscopic inguinal hernia repair in $38.5 \%$ of 19,188 pediatric patients, and prophylactic closure of the CPPV resulted in a risk reduction of $5.7 \%(95 \% \mathrm{Cl} 3.6 \text { to } 7.7 ; p<0.001)^{61}$. More specifically, Li et al. recommended laparoscopic contralateral repair in patients younger than three years old with initial left-sided inguinal hernia ${ }^{62}$.

To summarize, low-quality evidence from retrospective cohort studies suggests that open contralateral exploration with repair of a CPPV may prevent development of $\mathrm{MCIH}$ in children who present with a unilateral inguinal hernia. Though no firm conclusions can yet be drawn since high-level evidence comparing contralateral exploration to unilateral repair without contralateral exploration is lacking and there is extensive heterogeneity among the currently available evidence. 

or discharge from the NICU?

373 Recommendation (Level 2 evidence; Grade B): Postponing hernia repair until after discharge may be beneficial in terms of preventing respiratory difficulties and hernia recurrence. No significant differences were found for incarceration and reoperation rate.

Background

Controversy still exists about the timing of inguinal hernia repair in the premature population, in which the incidence of inguinal hernia rises to almost $20 \%^{63}$. Early hernia repair (i.e. before discharge from the NICU) potentially prevents complications including the risk of incarceration, whereas late repair (i.e. after discharge from the NICU) potentially decreases the risk for operative and postoperative anesthetic and surgical complications $s^{64}$. The timing of inguinal hernia repair in preterm infants should therefore represent a balance of the risks of hernia incarceration against postoperative respiratory complications ${ }^{64}$. In 2005 , the majority $(63 \%)$ of pediatric surgeons that were surveyed preferred to perform hernia repair before hospital discharge ${ }^{65}$. However, the risk of postoperative apnea is inversely related to gestational age and postconceptional age, and it is believed that postponing hernia repair surgery decreases the risk of postoperative apnea without increasing the risk of incarceration ${ }^{66,67}$.

Results

Seven retrospective cohort studies ( $n=2024$ patients) assessed the optimal timing of inguinal hernia repair in preterm infants (Appendix 3) ) $^{68-74}$. Within these studies, 1176 patients were operated on before NICU discharge and 848 patients underwent hernia repair after NICU discharge. Average gestational age and birth weight of the included patients ranged from 26.2 to 32.2 weeks and 740 to 1460 grams, respectively. The average waiting time from diagnosis to surgery ranged from 2.8 to 10.7 weeks, and surgical repair was performed at an average postconceptional age of 11.3 to 62.9 weeks. 

hernia repair before (18.1\%) and after (11.3\%) discharge (OR 1.42 [95\% Cl 0.87 to 2.34], 12=0\%, $p=0.16)^{74-79}$

Recurrence and reoperation ${ }^{78,80}$ rates occurred in $5.7 \%$ and $5.1 \%$ of the patients with early

401

402

403

404

405

\section{Discussion and summary}

Moderate-quality evidence from meta-analysis of retrospective cohort studies suggests that inguinal hernia repair performed after NICU discharge may reduce the risk of respiratory difficulties and hernia recurrence compared to repair before discharge. No differences could be demonstrated for incarceration and reoperation rate. However, the currently available evidence is limited and among the included studies, the patients' age at the time of inguinal hernia repair varied largely (11.3-62.9 weeks). Furthermore, follow-up duration was sometimes poorly reported ${ }^{74,77}$ or varied among the studies included for the outcome recurrence ${ }^{75,78,79}$. For the outcome reoperation, two studies were included: Sulkowski et al. reported reoperation as being either ipsilateral recurrence of inguinal hernia or occurrence of metachronous hernia ${ }^{80}$; The outcome reoperation in the study of Takahashi et al. 
included any complication requiring surgery. In both of the cases the indication for reoperation was cryptorchism instead of hernia recurrence ${ }^{78}$.

The results for this topic are in line with the results of a previous meta-analysis by Masoudian et al., who also demonstrated a significant increase in the odds of respiratory difficulty (OR 3.59 [95\% $\mathrm{Cl} 1.10$ to 11.75$], I^{2}=42 \%$ ) and recurrence (OR 4.12 [95\% $\mathrm{Cl} 1.17$ to 14.45$], l^{2}=0 \%$ ) if hernia repair was performed before NICU discharge. They also found no significant differences regarding incarceration rate, surgical complications and reoperation rate ${ }^{81}$.

\section{Question 5. In preterm infants, is regional anesthesia associated with better outcome compared to} general anesthesia?

Recommendation (Level 1 evidence; Grade B): Central regional anesthesia instead of general anesthesia may be considered in preterm infants requiring surgery for inguinal hernia repair, since it is associated with some decrease in the occurrence of postoperative apnea and decreased postoperative pain among this population.

\section{Background}

Preterm infants undergoing surgery with general anesthesia are susceptible to apneic episodes, with or without bradycardia, in the postoperative period. Alterations caused by apnea and bradycardia include a reduced cerebral blood flow and significant oxygen desaturations, yielding an increased risk of affecting neurodevelopmental outcome ${ }^{82,83}$. Additionally, there are increasing concerns that general anesthetics and sedative agents have a potential harmful effect on the child's developing brain ${ }^{34}$. According to the results of a systematic review by Jones et al., spinal anesthesia was initially not found to reduce the overall incidence of postoperative morbidity in preterm infants undergoing inguinal hernia repair. However, after exclusion of infants receiving ketamine from the analysis, spinal anesthesia rather than general anesthesia in preterm infants without receiving any sedatives reduced the risk of postoperative apnea by $47 \%$. In former preterm infants without preoperative apnea, spinal 
anesthesia may even reduce the risk of postoperative apnea by up to $66 \%$. In order to prevent one infant from having an episode of post-operative apnea, four infants needed to be treated with spinal anesthesia ${ }^{84}$.

\section{Results}

Thirteen articles describing eight randomized controlled trials were included in the meta-analysis for

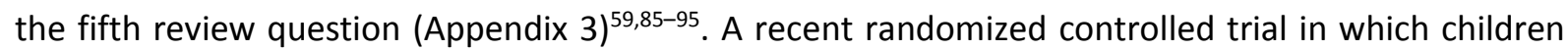
were randomly assigned to receive either awake-regional or sevoflurane-based general anesthesia for inguinal hernia repair in early infancy was included. Data of this General Anesthesia compared to Spinal anesthesia (GAS) trial, which reports both term and preterm patients, was extrapolated on preterm patients for some outcomes. The overall failure rate of regional anesthesia was reported to be $20 \%$, none of the studies reported failure rates of general anesthesia.

In preterm infants undergoing surgical hernia repair, the risk of apnea was not different between central regional anesthesia and general anesthesia (OR 0.68 [95\% $\mathrm{Cl} 0.37$ to 1.23$], l^{2}=6 \%$, $\mathrm{p}=0.20)^{88,91,96-99}$. Results of the per-protocol analysis, in which patients from the regional anesthesia group that required sedation or switched to general anesthesia were included in the general anesthesia group, showed that regional anesthesia was associated with a reduced risk of postoperative apnea (OR 0.46 [95\% Cl 0.22 to 0.96$\left.], l^{2}=11 \%, p=0.04\right)^{88,96-99}$. Subgroup analysis including only preterm infants with early (within one hour postoperative) postoperative apnea (OR 0.60 [ $95 \% \mathrm{Cl} 0.18$ to 1.98 ], $\left.I^{2}=31 \%, \mathrm{p}=0.41\right)^{91,97-99}$ or preterm infants with preoperative apnea's (OR 0.52 [95\% $\mathrm{Cl} 0.11$ to 2.45 ], $\left.I^{2}=3 \%, p=0.40\right)^{88,96,97}$ indicated no differences between regional and general anesthesia. The risk of postoperative apnea episodes requiring intervention (e.g. stimulation, assisted ventilation, continuous positive airway pressure, endo-tracheal intubation or administration of methylxanthine) was reduced after regional anesthesia (OR $0.11[95 \% \mathrm{Cl} 0.00$ to 2.51$], l^{2}=77 \%, \mathrm{p}=0.17$ ), although not reaching statistical significance ${ }^{88,96,99}$. 
postoperative hypotension (OR 0.83 [95\% $\mathrm{Cl} 0.01$ to 95.94$\left.], l^{2}=90 \%, p=0.94\right)^{88,101}$ was not different

476 between the regional versus general anesthesia group. Postoperative pain was significantly lower in 477 patients who had central regional anesthesia (OR $0.44[95 \% \mathrm{Cl} 0.31$ to 0.63$\left.], l^{2}=0 \%, p<0.001\right)^{59,88}$ (Table

4783 and Appendix 4) $)^{59}$. The GAS trial was the only study reporting neurodevelopmental outcome and 479 they demonstrated that there was no difference in neurodevelopmental outcome between the awakeregional anesthesia and general anesthesia group in terms of the mean composite cognitive score (0.169 [95\% $\mathrm{Cl}-2.30$ to 2.64$])$ at two years of follow-up ${ }^{95}$.

\section{Discussion and summary}

Moderate-quality evidence from meta-analysis of RCTs indicates that central regional anesthesia, without additional sedatives, may reduce the risk of postoperative apnea in premature infants undergoing inguinal hernia repair. It also suggests that central regional anesthesia is associated with a better postoperative pain control in premature infants undergoing inguinal hernia repair. However, central regional anesthesia is also reported to be associated with a $20 \%$ failure rate. There are some concerns on the quality of various studies included in the meta-analysis. Thereby, considerable variation in the classification to define postoperative apnea and subsequently the duration of apnea existed among the included studies, which complicated the comparison of this outcome. However, for most outcomes included, the majority of the evidence originates from the GAS study, which was judged as having a good quality and a low risk of bias. The GAS study defined postoperative apnea as "an unexplained episode of cessation of breathing for 20 seconds or longer, or a shorter respiratory pause associated with bradycardia, cyanosis, pallor, and/or marked hypotonia requiring intervention" 99,102 . 
Recommendation (Level 4 evidence; Grade C): Since high-level evidence comparing emergency and elective repair of asymptomatic irreducible ovarian hernias in girls is lacking and there is extensive heterogeneity among the currently available evidence, no clear recommendation can be made.

\section{Background}

Ovarian inguinal hernias comprise $13-22 \%$ of all hernias in female children ${ }^{103-106}$ and are most common in infants before one year of age ${ }^{104,107-109}$. Incarcerated inguinal hernias in girls involve the ovary in 58$82 \%^{110,111}$. Irreducible ovarian inguinal hernias are believed to potentially be at risk for ovarian torsion and it is assumed that ovarian torsion causes ovarian injury in girls with ovarian inguinal hernias ${ }^{112,113}$. In 1991, Boley et al. showed that in $27 \%$ of the girls with an ovarian inguinal hernia the ovary was twisted or infarcted at the time of surgery. Based on these findings, they suggested that asymptomatic irreducible ovarian hernias should be considered as any other incarceration, and emergency surgery should be performed if non-operative reduction was unsuccesful ${ }^{112}$. In 1993, the American Academy of Pediatrics Section of Surgery performed a survey in which $27 \%$ of the pediatric surgeons responded that they repair reducible ovarian hernias electively, $59 \%$ at the next available opportunity and $10 \%$ performed emergent repair. In 2003 , these results were $49 \%, 36 \%$ and $5 \%$, respectively. Irreducible asymptomatic ovaries were reported to be operated at the next available opportunity by $42 \%$ in 1993 and $50 \%$ in 2005 , while $44 \%$ and $32 \%$ operated urgently $y^{65,114}$.

\section{Results}

Twelve retrospective case series ( $n=506$ patients) were included in the systematic review, whereas none could be included for quantitative analysis of the results (Appendix 3) ${ }^{103,104,106,107,110-112,115-119}$. Several authors suggest that both reducible and irreducible asymptomatic ovarian inguinal hernias should be repaired within a few days following diagnosis ${ }^{104,108,109}$, whereas others state that asymptomatic irreducible ovaries should be treated with urgent manual, or if unsuccessful, operative reduction ${ }^{112,116}$. The reported incidence of ovarian strangulation in girls with irreducible hernias among 
the included studies was between $0-36 \%$ (Table 5) $)^{104,108,109,112}$. Turk et al. operated on 7 girls with

527 irreducible hernias within 24-72 hours after their presentation (semi-elective) and reported no

528 strangulations ${ }^{109}$. Esposito et al. performed surgical repair in 16 patients that presented with

529

530

531

532

533

534

535 asymptomatic irreducible hernias within 1-4 days after diagnosis and also reported no cases of strangulation or torsion. All patients underwent follow-up ultrasonography one year after surgery and none of the ovaries atrophied ${ }^{108}$. In contrast, Hirabayashi et al. evaluated 71 girls who were diagnosed as having asymptomatic ovarian hernias at a median age of 1.5 months, of whom 58 underwent surgery at a median age of 11 months, as their policy was to postpone surgery until 9 months of age. By that time the ovary had already reduced spontaneously into the abdomen in 35 (60\%) girls. In 22 (38\%) girls, and also in 13 girls who had not been preoperatively diagnosed with ovarian hernias, ovary was found in the hernia sac during surgery. There were no reports of ovarian torsion, yet in one patient the hernia sac including the fallopian tube and ovary was ligated ${ }^{107}$. Marinkovic et al. reported ovarian torsion in 35 girls (14\%) who presented with incarcerated hernia and subsequently performed salphingo-oophorectomy twice ${ }^{116}$. Lee et al. reported that ovaries were ischemic in $4.5 \%$ of incarcerated hernias ${ }^{110}$. In girls with ovarian torsion, the ovary was found to be strangulated in $55 \%{ }^{113}$. Chen at al. reported ovarian strangulation in $9 / 32$ female patients ( $<1$ year old) that presented with incarcerated ovarian hernias, and found that a larger ovary $\left(\geq 5 \mathrm{~cm}^{3}\right)$ was more likely for ovarian torsion. As the ovarian volume decreases with inclining age, female infants therefore have an increased risk for developing ovarian strangulation ${ }^{115}$.

\section{Discussion and summary}

All included studies were retrospective case series with low level of evidence. The studies were heterogeneous with respect to inclusion criteria, especially regarding the type of ovarian hernia (e.g. reducible/irreducible and symptomatic or asymptomatic), timing of surgery and outcome measures. Moreover, follow-up data were very limited. 
552 a large cohort $(n=1084)$ of female patients who underwent inguinal hernia repair. Their reported

553 incidences of ovarian herniation and ovarian strangulation were $21.7 \%$ and $6 \%$, respectively. In girls

554

555

556

557

558

559

560

561

562

563

564

565

566

567

568

569

570

571

572

573

574

575

576 with ovarian strangulation, the median time interval between diagnosis and surgery was 11.5 (1.320.5) days, and three patients underwent an emergency operation within 24 hours after diagnosis. No firm conclusions on the timing of surgery could be drawn because the exact time of occurrence of the inguinal hernia was unknown ${ }^{120}$.

Although repair within a few days may reduce the risk for ovarian torsion and strangulation, based on the currently available low quality evidence, no recommendation can be made regarding the timing of repair for asymptomatic irreducible ovarian inguinal hernias.

\section{Conclusion}

In this systematic review and Evidence-Based guideline, all currently available evidence pertinent to six pre-specified review questions, was assessed by the members of the EUPSA Evidence and Guidelines Committee. Based on the evidence included in this review, laparoscopic repair may be beneficial for children with inguinal hernia and preterm infants may benefit using central regional anesthesia and postponing surgery. However, no definite superiority was found and available evidence was of moderate to low quality. As inguinal hernia repair in children is a widely performed surgery, local circumstances may differ and recommendations may not apply to every clinical setting. For the optimal management of inguinal hernia repair a tailored approach is therefore recommended taking into consideration the local facilities, sources and expertise of the medical team involved.

\section{Summary of recommendations}

- Based on the currently available evidence there is no definite superiority of either the laparoscopic or open treatment strategy regarding perioperative (i.e. spermatic cord/vessel injury, ovarian lesion and bleeding) and postoperative (i.e. hematoma, edema, hydrocele, 
wound infection and testicular atrophy) complications, recurrence rate and development of metachronous contralateral inguinal hernia $(\mathrm{MClH})$. Laparoscopic inguinal hernia repair might be advantageous in children with bilateral inguinal hernia in terms of reduced operation time (Level 1 evidence; Grade B).

- Based on the currently available evidence there is no definite superiority for either the laparoscopic extra-peritoneal or trans-peritoneal approach regarding the occurrence of intraoperative (i.e. vessel injury and conversion to open surgery) or postoperative (i.e. hydrocele, wound infection and testicular atrophy) complications and recurrence rate. In comparison with the trans-peritoneal approach, the laparoscopic (unilateral and bilateral) extra-peritoneal approach may result in reduced operation time in children with inguinal hernia (Level 2 evidence; Grade B).

- Since high-level evidence comparing contralateral exploration to unilateral repair without contralateral exploration is lacking and there is extensive heterogeneity among the currently available evidence, no clear recommendation can be made (Level 2 and 3 evidence). respiratory difficulties and hernia recurrence. No significant differences were found for incarceration and reoperation rate. (Level 2 evidence; Grade B).

- Central regional anesthesia instead of general anesthesia may be considered in preterm infants requiring surgery for inguinal hernia repair, since it is associated with some decrease in the occurrence of postoperative apnea and decreased postoperative pain among this population (Level 1 evidence; Grade B).

- Since high-level evidence comparing emergency and elective repair of asymptomatic irreducible ovarian hernias in girls is lacking and there is extensive heterogeneity among the currently available evidence, no clear recommendation can be made (Level 4 evidence; Grade 


\section{Acknowledgements}

This work was supported by The Netherlands Organization for Health Research and Development (ZonMw), grant number 852001903.

\section{References}

1. Rajput A, Gauderer MWL, Hack M. Inguinal hernias in very low birth weight infants: Incidence and timing of repair. J Pediatr Surg. 1992;27(10):1322-1324. doi:10.1016/00223468(92)90287-H

2. Kumar VHS, Clive J, Rosenkrantz TS, Bourque MD, Hussain N. Inguinal hernia in preterm infants ( $\leq 32-$ Week Gestation). Pediatr Surg Int. 2002;18(2-3):147-152. doi:10.1007/s003830100631

3. Chang SJ, Chen JYC, Hsu CK, Chuang FC, Yang SSD. The incidence of inguinal hernia and associated risk factors of incarceration in pediatric inguinal hernia: a nation-wide longitudinal population-based study. Hernia. 2016;20(4):559-563. doi:10.1007/s10029-015-1450-x

4. Simons MP, Aufenacker T, Bay-Nielsen M, et al. European Hernia Society guidelines on the treatment of inguinal hernia in adult patients. Hernia. 2009;13(4):343-403. doi:10.1007/s10029-009-0529-7

5. HerniaSurge Group. International guidelines for groin hernia management. Hernia. 2018;22(1):1-165. doi:10.1007/s10029-017-1668-x

6. Moher D, Liberati A, Tetzlaff J, Altman DG, Group TP. Preferred Reporting Items for Systematic Reviews and Meta-Analyses: The PRISMA Statement. PLoS Med. 2009;6(7):e1000097. doi:10.1371/journal.pmed.1000097

7. Phillips B, Ball C, Sackett D, Badenoch D, Straus S, Haynes B DM. Oxford Centre for Evidencebased Medicine - Levels of Evidence (March 2009) - CEBM. https://www.cebm.net/2009/06/oxford-centre-evidence-based-medicine-levels-evidencemarch-2009/. Published 2009. Accessed April 1, 2020. 
629 8. Feng S, Zhao L, Liao Z, Chen X. Open Versus Laparoscopic Inguinal Herniotomy in Children: A

630

631

632

633

634

635

636

637

638

639

640

641

642

643

644

645

646

647

648

649

650

651

652

653

654
Systematic Review and Meta-Analysis Focusing on Postoperative Complications. Surg

Laparosc Endosc Percutan Tech. 2015;25(4):275-280. doi:10.1097/SLE.0000000000000161

9. Davies DA, Rideout DA, Clarke SA. The International Pediatric Endosurgery Group EvidenceBased Guideline on Minimal Access Approaches to the Operative Management of Inguinal Hernia in Children. J Laparoendosc Adv Surg Tech A. January 2017:lap.2016.0453. doi:10.1089/lap.2016.0453

10. Celebi S, Uysal Al, Inal FY, Yildiz A. A single-blinded, randomized comparison of laparoscopic versus open bilateral hernia repair in boys. J Laparoendosc Adv Surg Tech A. 2014;24(2):117121. doi:10.1089/lap.2013.0397

11. Chan KL, Hui WC, Tam PKH. Prospective randomized single-center, single-blind comparison of laparoscopic vs open repair of pediatric inguinal hernia. Surg Endosc. 2005;19(7):927-932. doi:10.1007/s00464-004-8224-3

12. Gause CD, Casamassima MGS, Yang J, et al. Laparoscopic versus open inguinal hernia repair in children $\leq 3$ : a randomized controlled trial. Pediatr Surg Int. 2017;33(3):367-376. doi:10.1007/s00383-016-4029-4

13. Yılmaz İnal F, Çelebi S, Uysal Ai, Yılmaz Y, Toptaş M, Daşkaya H. Tek Tarafıı Inguinal Herni Operasyonu Uygulanan Çocuklarda Açık ve Laparoskopik Cerrahi Tekniklerinin Anestezi Süresi, Postoperatif Ağrı ve Analjezik Tüketimi Üzerine Etkilerinin Karşılaştırılması. Haseki Tıp Bülteni. 2014;52(2):84-88. doi:10.4274/haseki.1265

14. Koivusalo Al, Korpela R, Wirtavuori K, Piiparinen S, Rintala RJ, Pakarinen MP. A Single-Blinded, Randomized Comparison of Laparoscopic Versus Open Hernia Repair in Children. Pediatrics. 2009;123(1):332-337. doi:10.1542/peds.2007-3752

15. Saranga Bharathi R, Arora M, Baskaran V. Pediatric inguinal hernia: laparoscopic versus open surgery. JSLS J Soc Laparoendosc Surg. 12(3):277-281.

http://www.ncbi.nlm.nih.gov/pubmed/18765052. Accessed August 14, 2018. 
655 16. Shalaby R, Ibrahem R, Shahin M, et al. Laparoscopic Hernia Repair versus Open Herniotomy in

656

657

658

659

660

661

662

663

664

665

666

667

668

669

670

671

672

673

674

675

676

677

678

679

Children: A Controlled Randomized Study. Minim Invasive Surg. 2012;2012:484135. doi:10.1155/2012/484135

17. Zhu X-Q，管文贤. Laparoscopic assisted extraperitoneal hernia sac high ligation vs traditional surgery for inguinal hernia in preschool children. World Chinese J Dig. 2015;23(13):2168. doi:10.11569/wcjd.v23.i13.2168

18. Zhu X-Q，管文贤. Laparoscopic assisted extraperitoneal hernia sac high ligation vs traditional surgery for inguinal hernia in preschool children. World Chinese J Dig. 2015;23(13):2168. doi:10.11569/wcjd.v23.i13.2168

19. Dreuning K, Maat S, Twisk J, van Heurn E, Derikx J. Laparoscopic versus open pediatric inguinal hernia repair: state-of-the-art comparison and future perspectives from a meta-analysis. Surg Endosc. 2019;33(10):3177-3191. doi:10.1007/s00464-019-06960-2

20. Alzahem A. Laparoscopic versus open inguinal herniotomy in infants and children: a metaanalysis. Pediatr Surg Int. 2011;27(6):605-612. doi:10.1007/s00383-010-2840-x

21. Dreuning K, Maat S, Twisk J, van Heurn E, Derikx J. Laparoscopic versus open pediatric inguinal hernia repair: state-of-the-art comparison and future perspectives from a meta-analysis. Surg Endosc. 2019;33(10):3177-3191. doi:10.1007/s00464-019-06960-2

22. Speck KE, Smith AK. Paediatric Laparoscopic Inguinal Hernia Repair: a Review of Techniques. Society of American Gastrointestinal and Endoscopic Surgeons, SAGES. https://www.sages.org/wiki/pediatric-laparoscopic-inguinal-hernia-repair-a-review-oftechniques/. Published 2013. Accessed April 17, 2020.

23. Shalaby R, Ismail M, Dorgham A, et al. Laparoscopic hernia repair in infancy and childhood: evaluation of 2 different techniques. J Pediatr Surg. 2010;45(11):2210-2216. doi:10.1016/J.JPEDSURG.2010.07.004

24. Korkmaz M, Güvenç BH. Comparison of single-port percutaneous extraperitoneal repair and 
three-port mini-laparoscopic repair for pediatric inguinal hernia. J Laparoendosc Adv Surg Tech. 2018;28(3):337-342. doi:10.1089/lap.2016.0223

25. Wang F, Zhong H, Shou T, Chen Y, Zhao J. Single-site laparoscopic percutaneous extraperitoneal closure versus modified transumbilical two-port laparoscopic suturing of the hernia sac for the treatment of pediatric inguinal hernia: Comparison of the outcomes of two different approaches. J Laparoendosc Adv Surg Tech. 2019;29(1):103-108. doi:10.1089/lap.2018.0405

26. Bharathi RS, Dabas AK, Arora M, Baskaran V. Laparoscopic ligation of internal ring - Three ports versus single-port technique: Are working ports necessary? J Laparoendosc Adv Surg Tech. 2008;18(6):891-894. doi:10.1089/lap.2007.0246

27. Shalaby R, Ismail M, Dorgham A, et al. Laparoscopic hernia repair in infancy and childhood: evaluation of 2 different techniques. J Pediatr Surg. 2010;45(11):2210-2216. doi:10.1016/J.JPEDSURG.2010.07.004

28. Nataraja RM, Mahomed AA. Systematic review for paediatric metachronous contralateral inguinal hernia: a decreasing concern. Pediatr Surg Int. 2011;27(9):953-961. doi:10.1007/s00383-011-2919-z

29. Hoshino $M$, Sugito $K$, Kawashima $H$, et al. Prediction of contralateral inguinal hernias in children: a prospective study of 357 unilateral inguinal hernias. Hernia. 2013. doi:10.1007/s10029-013-1099-2

30. Dreuning KMA, ten Broeke CEM, Twisk JWR, et al. Diagnostic accuracy of preoperative ultrasonography in predicting contralateral inguinal hernia in children: a systematic review and meta-analysis. Eur Radiol. July 2018. doi:10.1007/s00330-018-5625-6

31. Erdoğan D, Karaman I, Aslan MK, Karaman A, Çavuşoğlu YH. Analysis of 3776 pediatric inguinal hernia and hydrocele cases in a tertiary center. J Pediatr Surg. 2013;48(8):1767-1772. doi:10.1016/J.JPEDSURG.2012.09.048

32. Kokorowski PJ, Wang HH, Routh JC, Hubert KC, Nelson CP. Evaluation of the contralateral 
inguinal ring in clinically unilateral inguinal hernia: a systematic review and meta-analysis. Hernia. 2013. doi:10.1007/s10029-013-1146-z

33. Ein SH, Njere I, Ein A. Six thousand three hundred sixty-one pediatric inguinal hernias: a 35year review. J Pediatr Surg. 2006;41(5):980-986. doi:10.1016/J.JPEDSURG.2006.01.020

34. Andropoulos DB, Greene MF. Anesthesia and Developing Brains - Implications of the FDA Warning. N Engl J Med. 2017;376(10):905-907. doi:10.1056/NEJMp1700196

35. Gupta DK, Rohatgi M. Inguinal hernia in children: An Indian experience. Pediatr Surg Int. 1993;8(6):466-468. http://ovidsp.ovid.com/ovidweb.cgi?T=JS\&CSC=Y\&NEWS=N\&PAGE=fulltext\&D=emed6\&AN=2 3336015http://digitaal.uba.uva.nl:9003/uvalinker?sid=OVID:embase\&id=pmid:\&id=doi:\&issn=01790358\&isbn $=\&$ volume $=8 \&$ issue $=6 \&$ spage $=466 \&$ pages $=466$ 468\&date $=1993 \&$ title $=$ Pediatric + Surge.

36. Maillet OP, Garnier S, Dadure C, et al. Inguinal hernia in premature boys: should we systematically explore the contralateral side? J Pediatr Surg. 2014;49(9):1419-1423.

37. Rescorla FJ, Grosfeld JL. Inguinal hernia repair in the perinatal period and early infancy: clinical considerations. J Pediatr Surg. 1984;19(6):832-837.

38. Disma N, Withington D, McCann ME, et al. Surgical practice and outcome in 711 neonates and infants undergoing hernia repair in a large multicenter RCT: Secondary results from the GAS Study. J Pediatr Surg. 2018;53(9):1643-1650. doi:10.1016/j.jpedsurg.2018.01.003

39. Clausen EG, Jake RJ, Binkley FM. Contralateral inguinal exploration of unilateral hernia in infants and children. Surgery. 1958;44(4):735-740.

40. Gunnlaugsson GH, Dawson B, Lynn HB. Treatment of inguinal hernia in infants and children: experience with contralateral exploration. Mayo Clin Proc. 1967;42(3):129-136.

41. Holcomb Jr GW. ROUTINE BILATERAL INGUINAL HERNIA REPAIR. AN EVALUATION of the PROCEDURE in INFANTS and CHILDREN. Am J Dis Child. 1965;109(2):114-120. 
http://ovidsp.ovid.com/ovidweb.cgi?T=JS\&CSC=Y\&NEWS=N\&PAGE=fulltext\&D=emcl1\&AN=28 6028625http://digitaal.uba.uva.nl:9003/uva-

linker?sid=OVID:embase\&id=pmid:\&id=doi:\&issn=0002-

922X\&isbn=\&volume=109\&issue $=2 \&$ spage $=114 \&$ pages $=114-$

120\&date $=1965 \&$ title $=$ American $+J o u$.

42. Kalani BP, Sogani KC. Bilateral exploration in children with unilateral inguinal hernia. Indian Pediatr. 1972;9(1):26-28.

43. Kling S, Demarco R, Martinez-Caro A. ROUTINE BILATERAL EXPLORATION FOR INGUINAL HERNIA IN CHILDREN--YES OR NO? Can J Surg. 1963;6:414-418.

44. Laufer A, Eyal Z. CONTRALATERAL INGUINAL EXPLORATION in CHILD with UNILATERAL HERNIA. Arch. 1962;(3):418-424. http://ovidsp.ovid.com/ovidweb.cgi?T=JS\&CSC=Y\&NEWS=N\&PAGE=fulltext\&D=emcl1\&AN=28 1277679http://digitaal.uba.uva.nl:9003/uvalinker?sid=OVID:embase \&id=pmid: $\&$ id=doi: $\&$ issn=\&isbn=\&volume=85\&issue=3\&spage=418\& pages $=418-424 \&$ date $=1962 \&$ title $=\&$ atitle $=$ CONTRALATERAL.+

45. Martin Jr. RS. The case for bilateral exploration of inguinal canals in pediatric patients presenting unilateral inguinal hernias. Am Surg. 1961;27:182-185.

46. Rothenberg RE, Barnett T. Bilateral herniotomy in infants and children. Surgery. $1955 ; 37(6): 947-950$.

http://ovidsp.ovid.com/ovidweb.cgi?T=JS\&CSC=Y\&NEWS=N\&PAGE=fulltext\&D=emcl1\&AN=28 0901284http://digitaal.uba.uva.nl:9003/uvalinker?sid=OVID:embase\&id=pmid:\&id=doi:\&issn=00396060\&isbn=\&volume=37\&issue=6\&spage=947\&pages $=947-$ 950\&date $=1955 \&$ title=Surgery\&atitl.

47. Gilbert MG, Davis HC, Shaver WA. Bilateral inguinal herniorrhaphies on infants and children. Am J Dis Child. 1961;102(1):4-7. 
http://ovidsp.ovid.com/ovidweb.cgi?T=JS\&CSC=Y\&NEWS=N\&PAGE=fulltext\&D=emcl1\&AN=28 1079668http://digitaal.uba.uva.nl:9003/uva-

linker?sid=OVID:embase\&id=pmid:\&id=doi:\&issn=0002-

922X\&isbn=\&volume $=102 \&$ issue $=1 \&$ spage $=4 \&$ pages $=4-$

7\&date=1961\&title=American+Journal+o.

48. Solomon JR. The practice and implications of contralateral exploration in children with unilateral inguinal hernia. Aust N Z J Surg. 1967;37(2):125-133.

49. Tepas 3rd JJ, Stafford PW. Timing of automatic contralateral groin exploration in male infants with unilateral hernias. Am Surg. 1986;52(2):70-71.

50. Wright JE. Inguinal hernia in girls: desirability and dangers of bilateral exploration. Aust Paediatr J. 1982;18(1):55-57.

51. Lugo Vicente HL. The pediatric inguinal hernia: is contralateral exploration justified? Bol Asoc Med P R. 1995;87(1):8-11.

52. McLaughlin Jr CW, Coe JD. Inguinal hernia in pediatric patients. Am J Surg. 1960;99(1):45-47. http://ovidsp.ovid.com/ovidweb.cgi?T=JS\&CSC=Y\&NEWS=N\&PAGE=fulltext\&D=emcl1\&AN=28 1186941http://digitaal.uba.uva.nl:9003/uvalinker?sid=OVID:embase\&id=pmid:\&id=doi:10.1016\%2F0002-9610\%252860\%2529902476\&issn=0002-9610\&isbn=\&volume=99\&issue=1\&spage=45\&pages $=$

53. Moss RL, Hatch Jr. El. Inguinal hernia repair in early infancy. Am J Surg. 1991;161(5):596-599.

54. Rowe MI, Copelson LW, Clatworthy HW. The patent processus vaginalis and the inguinal hernia. J Pediatr Surg. 1969;4(1):102-107. http://www.ncbi.nlm.nih.gov/pubmed/5779274.

55. Simpson TE, Gunnlaugsson GH, Dawson B, Lynn HB. Further experience with bilateral operations for inguinal hernia in infants and children. Ann Surg. 1969;169(3):450-454. http://ovidsp.ovid.com/ovidweb.cgi?T=JS\&CSC=Y\&NEWS=N\&PAGE=fulltext\&D=emcl1\&AN=28 9080947http://digitaal.uba.uva.nl:9003/uvalinker?sid=OVID:embase\&id=pmid:\&id=doi:10.1097\%2F00000658-196903000- 
56. Zampieri N, Zuin V, Ottolenghi A, Camoglio FS. Contralateral exploration for unilateral inguinal hernia in females: risk factors and surgical findings. Hernia. 2008;12(5):511-514. http://ovidsp.ovid.com/ovidweb.cgi?T=JS\&CSC=Y\&NEWS=N\&PAGE=fulltext\&D=med6\&AN=18 496730http://digitaal.uba.uva.nl:9003/uvalinker?sid=OVID:medline\&id=pmid:18496730\&id=doi:10.1007\%2Fs10029-008-0384y\&issn=1265-4906\&isbn=\&volume=12\&issue $=5 \&$ spage $=511 \&$ pages $=511$.

57. Jona JZ. The incidence of positive contralateral inguinal exploration among preschool children-a retrospective and prospective study. J Pediatr Surg. 1996;31(5):656-660.

58. Surana R, Puri P. Fate of patent processus vaginalis: A case against routine contralateral exploration for unilateral inguinal hernia in children. Pediatr Surg Int. 1993;8(5):412-414. http://ovidsp.ovid.com/ovidweb.cgi?T=JS\&CSC=Y\&NEWS=N\&PAGE=fulltext\&D=emed6\&AN=2 3258775http://digitaal.uba.uva.nl:9003/uvalinker?sid=OVID:embase\&id=pmid:\&id=doi:\&issn=01790358\&isbn $=\&$ volume $=8 \&$ issue $=5 \&$ spage $=412 \&$ pages $=412-$ 414\&date=1993\&title=Pediatric+Surge.

59. Disma N, Withington D, McCann ME, et al. Surgical practice and outcome in 711 neonates and infants undergoing hernia repair in a large multicenter RCT: Secondary results from the GAS Study. J Pediatr Surg. 2018;53(9):1643-1650. doi:10.1016/j.jpedsurg.2018.01.003

60. Chong AJ, Fevrier HB, Herrinton LJ. Long-term follow-up of pediatric open and laparoscopic inguinal hernia repair. J Pediatr Surg. 2019;54(10):2138-2144. doi:10.1016/j.jpedsurg.2019.01.064

61. Muensterer OJ, Gianicolo E. Contralateral processus closure to prevent metachronous inguinal hernia: A systematic review. Int J Surg. 2019;68:11-19. doi:10.1016/j.ijsu.2019.06.001

62. Li Y, Wu Y, Wang $C$, et al. Incidence of pediatric metachronous contralateral inguinal hernia and the relationship with contralateral patent processus vaginalis. Surg Endosc. 
2019;33(4):1087-1090. doi:10.1007/s00464-018-6359-x

63. Kumar VHS, Clive J, Rosenkrantz TS, Bourque MD, Hussain N. Inguinal hernia in preterm infants ( $\leq 32-$ Week Gestation). Pediatr Surg Int. 2002;18(2-3):147-152. doi:10.1007/s003830100631

64. Wang KS, Committee on F, Newborn AA of P, Section on Surgery AA of P. Assessment and management of inguinal hernia in infants. Pediatrics. 2012;130(4):768-773. doi:10.1542/peds.2012-2008

65. Antonoff MB, Kreykes NS, Saltzman DA, Acton RD. American Academy of Pediatrics Section on Surgery hernia survey revisited. J Pediatr Surg. 2005;40(6):1009-1014. doi:10.1016/j.jpedsurg.2005.03.018

66. Cote CJ, Zaslavsky A, Downes JJ, et al. Postoperative Apnea in Former Preterm Infants after Inguinal Herniorrhaphy. Anesthesiology. 1995;82(4):809-822. doi:10.1097/00000542199504000-00002

67. Crankson S, Al Tawil K, Al Namshan M, et al. Management of inguinal hernia in premature infants: 10-year experience. J Indian Assoc Pediatr Surg. 2015;20(1):21. doi:10.4103/09719261.145440

68. Khan FA, Zeidan N, Larson SD, Taylor JA, Islam S. Inguinal hernias in premature neonates: exploring optimal timing for repair. Pediatr Surg Int. 2018;34(11):1157-1161. doi:10.1007/s00383-018-4356-8

69. Lee SL, Gleason JM, Sydorak RM. A critical review of premature infants with inguinal hernias: optimal timing of repair, incarceration risk, and postoperative apnea. J Pediatr Surg. 2011;46(1):217-220. doi:10.1016/j.jpedsurg.2010.09.094

70. Pandey R, Dako J, Venus S, Kumar D, Mhanna M. Early versus late inguinal hernia repair in extremely low-birthweight infants. J Matern Neonatal Med. 2017;30(20):2457-2460. doi:10.1080/14767058.2016.1253059

71. Sulkowski JP, Cooper JN, Duggan EM, et al. Does timing of neonatal inguinal hernia repair 
72. Takahashi A, Toki F, Yamamoto H, Otake S, Oki Y, Kuwano H. Outcomes of herniotomy in premature infants: Recent 10 year experience. Pediatr Int. 2012;54(4):491-495. doi:10.1111/j.1442-200X.2012.03607.x

73. Youn JK, Kim H-Y, Huh Y-J, et al. Inguinal hernia in preterms in neonatal intensive care units: Optimal timing of herniorrhaphy and necessity of contralateral exploration in unilateral presentation. J Pediatr Surg. 2018;53(11):2155-2159. doi:10.1016/j.jpedsurg.2018.02.056

74. Crankson S, Al Tawil K, Al Namshan M, et al. Management of inguinal hernia in premature infants: 10-year experience. J Indian Assoc Pediatr Surg. 2015;20(1):21. doi:10.4103/09719261.145440

75. Khan FA, Zeidan N, Larson SD, Taylor JA, Islam S. Inguinal hernias in premature neonates: exploring optimal timing for repair. Pediatr Surg Int. 2018;34(11):1157-1161. doi:10.1007/s00383-018-4356-8

76. Lee SL, Gleason JM, Sydorak RM. A critical review of premature infants with inguinal hernias: optimal timing of repair, incarceration risk, and postoperative apnea. J Pediatr Surg. 2011;46(1):217-220. doi:10.1016/j.jpedsurg.2010.09.094

77. Pandey R, Dako J, Venus S, Kumar D, Mhanna M. Early versus late inguinal hernia repair in extremely low-birthweight infants. J Matern Neonatal Med. 2017;30(20):2457-2460. doi:10.1080/14767058.2016.1253059

78. Takahashi A, Toki F, Yamamoto H, Otake S, Oki Y, Kuwano H. Outcomes of herniotomy in premature infants: Recent 10 year experience. Pediatr Int. 2012;54(4):491-495. doi:10.1111/j.1442-200X.2012.03607.x

79. Youn JK, Kim H-Y, Huh Y-J, et al. Inguinal hernia in preterms in neonatal intensive care units: Optimal timing of herniorrhaphy and necessity of contralateral exploration in unilateral presentation. J Pediatr Surg. 2018;53(11):2155-2159. doi:10.1016/j.jpedsurg.2018.02.056 
81. Masoudian $\mathrm{P}$, Sullivan KJ, Mohamed H, Nasr A. Optimal timing for inguinal hernia repair in premature infants: a systematic review and meta-analysis. J Pediatr Surg. 2019;54(8):15391545. doi:10.1016/j.jpedsurg.2018.11.002

82. Perlman JM, Volpe JJ. Episodes of apnea and bradycardia in the preterm newborn: impact on cerebral circulation. Pediatrics. 1985;76(3):333-338.

http://www.ncbi.nlm.nih.gov/pubmed/4034294. Accessed May 11, 2020.

83. Cote CJ, Zaslavsky A, Downes JJ, et al. Postoperative Apnea in Former Preterm Infants after Inguinal Herniorrhaphy. Anesthesiology. 1995;82(4):809-822. doi:10.1097/00000542199504000-00002

84. Jones LJ, Craven PD, Lakkundi A, Foster JP, Badawi N. Regional (spinal, epidural, caudal) versus general anaesthesia in preterm infants undergoing inguinal herniorrhaphy in early infancy. Cochrane Database Syst Rev. 2015;2015(6). doi:10.1002/14651858.CD003669.pub2

85. Welborn LG, Rice LJ, Hannallah RS, Broadman LM, Ruttimann UE, Fink R. Postoperative Apnea in Former Preterm Infants: Prospective Comparison of Spinal and General Anesthesia. Anesthesiology. 1990;72(5):838-842. doi:10.1097/00000542-199005000-00012

86. McCann ME, Withington DE, Arnup SJ, et al. Differences in Blood Pressure in Infants After General Anesthesia Compared to Awake Regional Anesthesia (GAS Study-A Prospective Randomized Trial). Anesth Analg. 2017;125(3):837-845. doi:10.1213/ANE.0000000000001870

87. Frawley G, Bell G, Disma N, et al. Predictors of Failure of Awake Regional Anesthesia for Neonatal Hernia Repair. Anesthesiology. 2015;123(1):55-65. doi:10.1097/aln.0000000000000708

88. Somri M, Gaitini L, Vaida S, Collins G, Sabo E, Mogilner G. Postoperative outcome in high-risk infants undergoing herniorrhaphy: Comparison between spinal and general anaesthesia. Anaesthesia. 1998;53(8):762-766. doi:10.1046/j.1365-2044.1998.00431.x

89. Kunst G, Linderkamp O, Holle R, Motsch J, Martin E. The proportion of high risk preterm 
infants with postoperative apnea and bradycardia is the same after general and spinal anesthesia. Can J Anaesth. 1999;46(1):94-95. doi:10.1007/BF03012527

90. Williams JM, Stoddart PA, Williams SAR, Wolf AR. Post-operative recovery after inguinal herniotomy in ex-premature infants: Comparison between sevoflurane and spinal anaesthesia. Br J Anaesth. 2001;86(3):366-371. doi:10.1093/bja/86.3.366

91. Das B, Batra YK, Panda NB, Rao KLN. Analgesia in the immediate postoperative period in infants undergoing inguinal herniorraphy: A comparison between spinal and general anaesthesia. J Anaesthesiol Clin Pharmacol. 2005;21(2):137-142.

92. Krane EJ, Haberkern CM, Jacobson LE. Postoperative apnea, bradycardia, and oxygen desaturation in formerly premature infants: prospective comparison of spinal and general anesthesia. Anesth Analg. 1995;80(1):7-13. doi:10.1097/00000539-199501000-00003

93. McCann ME, de Graaff JC, Dorris L, et al. Neurodevelopmental outcome at 5 years of age after general anaesthesia or awake-regional anaesthesia in infancy (GAS): an international, multicentre, randomised, controlled equivalence trial. Lancet. 2019;393(10172):664-677. doi:10.1016/S0140-6736(18)32485-1

94. Davidson AJ, Morton NS, Arnup SJ, et al. Apnea after Awake Regional and General Anesthesia in Infants: The General Anesthesia Compared to Spinal Anesthesia Study--Comparing Apnea and Neurodevelopmental Outcomes, a Randomized Controlled Trial. Anesthesiology. 2015;123(1):38-54. doi:10.1097/ALN.0000000000000709

95. Davidson AJ, Disma N, de Graaff JC, et al. Neurodevelopmental outcome at 2 years of age after general anaesthesia and awake-regional anaesthesia in infancy (GAS): an international multicentre, randomised controlled trial. Lancet. 2016;387(10015):239-250. doi:10.1016/S0140-6736(15)00608-X

96. Welborn LG, Rice LJ, Hannallah RS, Broadman LM, Ruttimann UE, Fink R. Postoperative Apnea in Former Preterm Infants: Prospective Comparison of Spinal and General Anesthesia. Anesthesiology. 1990;72(5):838-842. doi:10.1097/00000542-199005000-00012 
97. Kunst G, Linderkamp O, Holle R, Motsch J, Martin E. The proportion of high risk preterm infants with postoperative apnea and bradycardia is the same after general and spinal anesthesia. Can J Anaesth. 1999;46(1):94-95. doi:10.1007/BF03012527

98. Williams JM, Stoddart PA, Williams SAR, Wolf AR. Post-operative recovery after inguinal herniotomy in ex-premature infants: Comparison between sevoflurane and spinal anaesthesia. Br J Anaesth. 2001;86(3):366-371. doi:10.1093/bja/86.3.366

99. Davidson AJ, Morton NS, Arnup SJ, et al. Apnea after Awake Regional and General Anesthesia in Infants: The General Anesthesia Compared to Spinal Anesthesia Study--Comparing Apnea and Neurodevelopmental Outcomes, a Randomized Controlled Trial. Anesthesiology. 2015;123(1):38-54. doi:10.1097/ALN.0000000000000709

100. Krane EJ, Haberkern CM, Jacobson LE. Postoperative apnea, bradycardia, and oxygen desaturation in formerly premature infants: prospective comparison of spinal and general anesthesia. Anesth Analg. 1995;80(1):7-13. doi:10.1097/00000539-199501000-00003

101. McCann ME, Withington DE, Arnup SJ, et al. Differences in Blood Pressure in Infants After General Anesthesia Compared to Awake Regional Anesthesia (GAS Study-A Prospective Randomized Trial). Anesth Analg. 2017;125(3):837-845. doi:10.1213/ANE.0000000000001870

102. National Institutes of Health Consensus Development Conference on Infantile Apnea and Home Monitoring, Sept 29 to Oct 1, 1986. Pediatrics. 1987;79(2):292-299. http://www.ncbi.nlm.nih.gov/pubmed/3808807. Accessed May 11, 2020.

103. Esposito C, Gargiulo F, Farina A, et al. Laparoscopic Treatment of Inguinal Ovarian Hernia in Female Infants and Children: Standardizing the Technique. J Laparoendosc Adv Surg Tech. 2019;29(4):568-572. doi:10.1089/lap.2018.0630

104. Takehara H, Hanaoka J, Arakawa Y. Laparoscopic strategy for inguinal ovarian hernias in children: when to operate for irreducible ovary. J Laparoendosc Adv Surg Tech A. 2009;19 Suppl 1(s1):S129-31. doi:10.1089/lap.2008.0204.supp

105. Scherer LR, Grosfeld JL. Inguinal hernia and umbilical anomalies. Pediatr Clin North Am. 
1993;40(6):1121-1131. doi:10.1016/s0031-3955(16)38652-7

106. Turk E, Fescekoglu OR, Acari C, et al. Sliding Hernias in Female Children. Acta Chir Belg. 2013;113(4):281-284. doi:10.1080/00015458.2013.11680928

107. Hirabayashi T, Ueno S, Hirakawa H, Tei E, Mori M. Surgical Treatment of Inguinal Hernia with Prolapsed Ovary in Young Girls: Emergency Surgery or Elective Surgery. Tokai J Exp Clin Med. 2017;42(2):89-95. http://www.ncbi.nlm.nih.gov/pubmed/28681369. Accessed October 11, 2019.

108. Esposito C, Gargiulo F, Farina A, et al. Laparoscopic Treatment of Inguinal Ovarian Hernia in Female Infants and Children: Standardizing the Technique. J Laparoendosc Adv Surg Tech. 2019;29(4):568-572. doi:10.1089/lap.2018.0630

109. Turk E, Fescekoglu OR, Acari C, et al. Sliding Hernias in Female Children. Acta Chir Belg. 2013;113(4):281-284. doi:10.1080/00015458.2013.11680928

110. Lee SR. Efficacy of laparoscopic herniorrhaphy for treating incarcerated pediatric inguinal hernia. Hernia. 2018;22(4):671-679. doi:10.1007/s10029-017-1655-2

111. Merriman TE, Auldist AW. Ovarian torsion in inguinal hernias. Pediatr Surg Int. 2000;16(56):383-385. doi:10.1007/s003830000428

112. Boley SJ, Cahn D, Lauer T, Weinberg G, Kleinhaus S. The irreducible ovary: a true emergency. J Pediatr Surg. 1991;26(9):1035-1038. http://www.ncbi.nlm.nih.gov/pubmed/1941479. Accessed June 7, 2018.

113. Merriman TE, Auldist AW. Ovarian torsion in inguinal hernias. Pediatr Surg Int. 2000;16(56):383-385. doi:10.1007/s003830000428

114. Wiener ES, Touloukian RJ, Rodgers BM, et al. Hernia survey of the Section on Surgery of the American Academy of Pediatrics. J Pediatr Surg. 1996;31(8):1166-1169. doi:10.1016/s00223468(96)90110-4

115. Chen Y, Peng X-Z, Lu W, et al. Risk Factors for Strangulated Ovarian Hernia in Female Infants: the Role of Ovarian Volume. Curr Med Sci. 2018;38(6):1032-1037. doi:10.1007/s11596-018- 
967

968

969

970

971

972

973

974

975

976

977

978

979

980

981

982

983

984

985

986

987

988

989

990

991

116. Marinković S, Kantardzić M, Bukarica S, Grebeldinger S, Pajić M. When to operate nonreducible ovary? Med Pregl. 51(11-12):537-540.

http://www.ncbi.nlm.nih.gov/pubmed/10081276. Accessed April 1, 2020.

117. Stylianos S, Jacir NN, Harris BH. Incarceration of inguinal hernia in infants prior to elective repair. J Pediatr Surg. 1993;28(4):582-583. doi:10.1016/0022-3468(93)90665-8

118. Huang C-S, Luo C-C, Chao H-C, Chu S-M, Yu Y-J, Yen J-B. The presentation of asymptomatic palpable movable mass in female inguinal hernia. Eur J Pediatr. 2003;162(7-8):493-495. doi:10.1007/s00431-003-1226-7

119. Houben $\mathrm{CH}$, Chan KWE, Mou JWC, Tam YH, Lee KH. Irreducible inguinal hernia in children: how serious is it? J Pediatr Surg. 2015;50(7):1174-1176. doi:10.1016/j.jpedsurg.2014.10.018

120. Dreuning KM, Barendsen RW, van Trotsenburg AP, et al. Inguinal hernia in girls: a retrospective analysis of over 1000 patients. J Pediatr Surg. March 2020. doi:10.1016/J.JPEDSURG.2020.03.015 
Figure 1. PRISMA flow chart of the study selection for all questions (Q1-Q6).

Appendix 1. PRISMA flow diagram of the study selection and checklist.
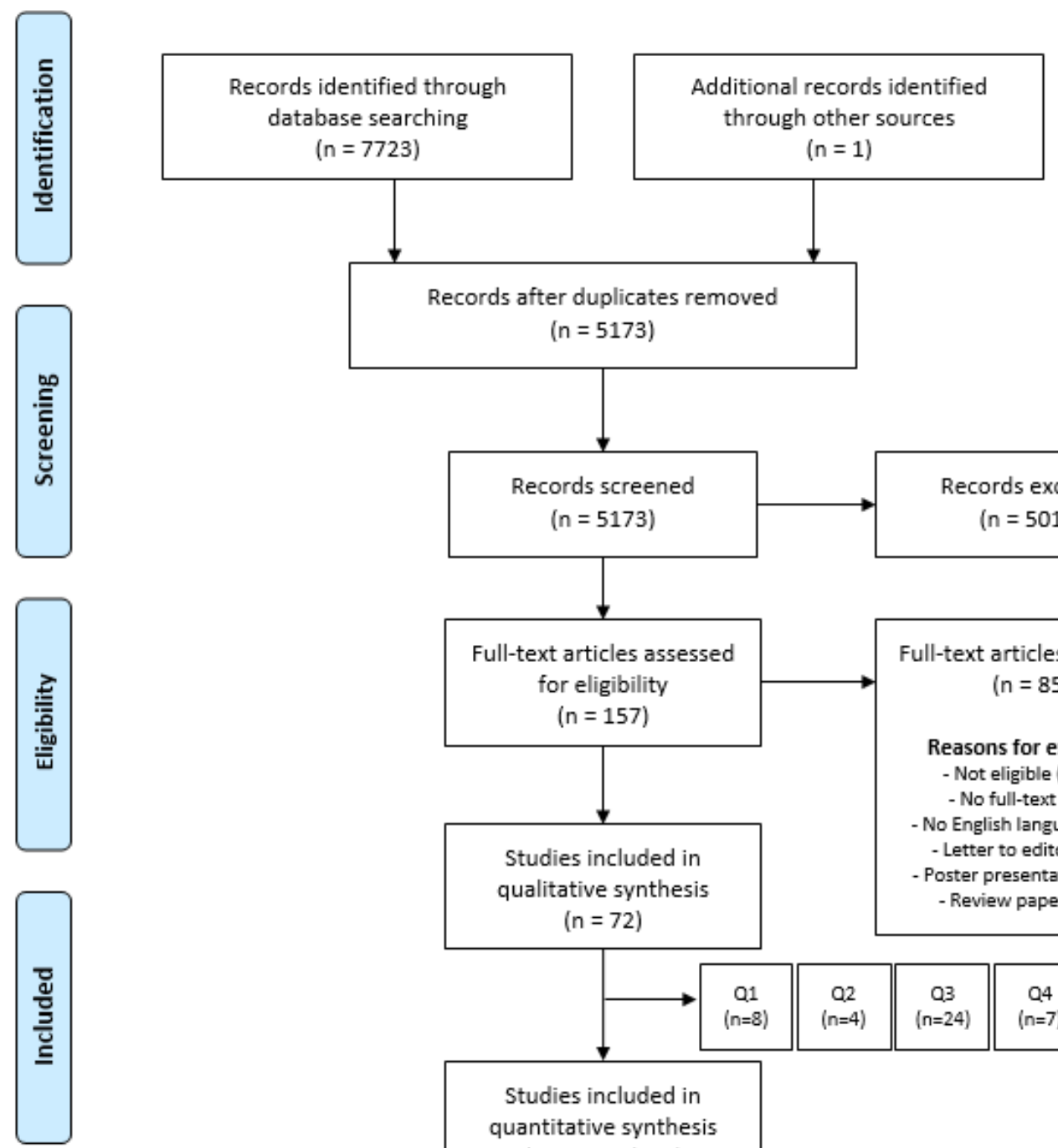

$$
(n=5173)
$$
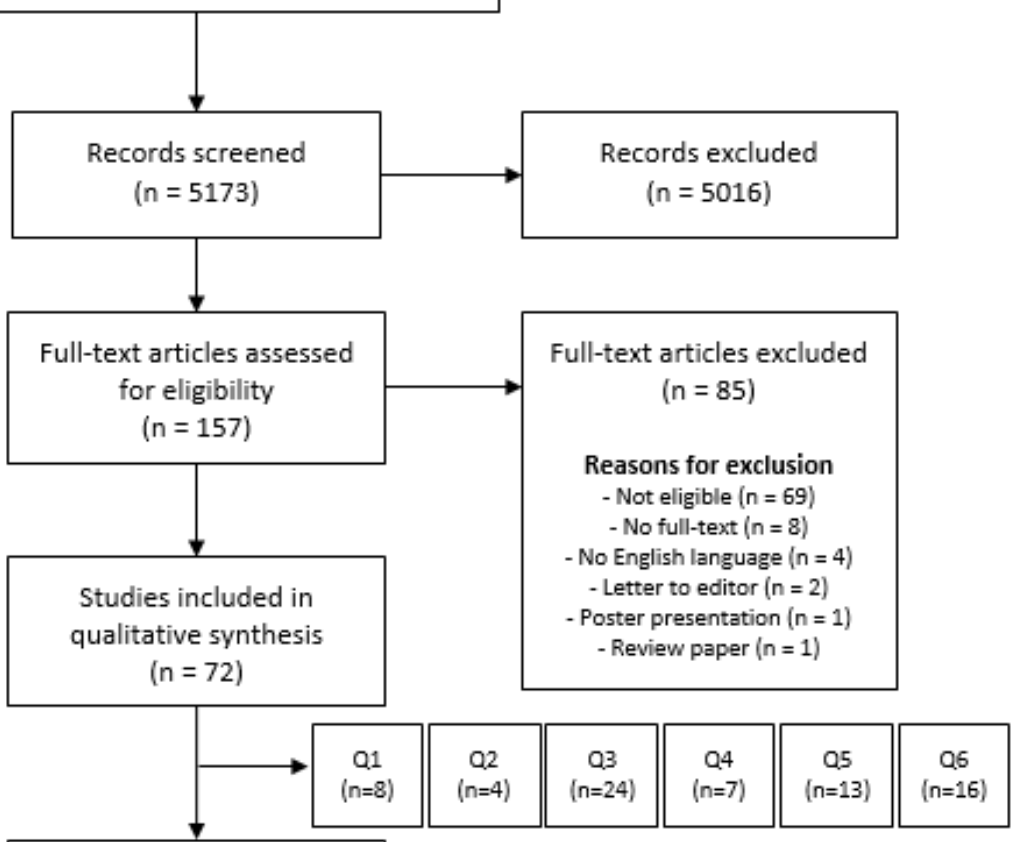

Studies included in quantitative synthesis (meta-analysis) $(n=27)$

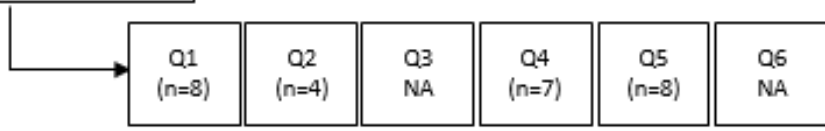


1000

1001

1002 


\section{Table 1. Outcome measures for the six review questions}

\begin{tabular}{|c|c|c|}
\hline Review questions & $\begin{array}{l}\text { Primary outcome } \\
\text { measure(s) }\end{array}$ & Secondary outcome measure(s) \\
\hline $\begin{array}{l}\text { 1. Is laparoscopic hernia repair associated with better outcome compared } \\
\text { to open repair? }\end{array}$ & $\begin{array}{l}1.1 \text { Complications }^{a} \\
1.2 \text { recurrence rate }\end{array}$ & $\begin{array}{l}\text { 1.3 Incidence of } \mathrm{MClH} \\
\text { 1.4 Duration of surgery (including anesthesia) } \\
\text { 1.5 Length of hospital stay } \\
\text { 1.6 Time to full recovery }\end{array}$ \\
\hline $\begin{array}{l}\text { 2. Which laparoscopic technique is associated with better outcome: the } \\
\text { extra-peritoneal approach or trans-peritoneal approach? }\end{array}$ & 2.1 Recurrence rate & $\begin{array}{l}\text { 2.2 Duration of surgery (including anesthesia) } \\
\text { 2.3 Conversion to open surgery } \\
\text { 2.4 Complications }{ }^{\text {a }}\end{array}$ \\
\hline $\begin{array}{l}\text { 3. Should contralateral inguinal exploration be performed at the time of } \\
\text { open unilateral inguinal hernia repair? }\end{array}$ & 3.1 Incidence of $\mathrm{MClH}$ & $\begin{array}{l}\text { 3.2 Complications }{ }^{\mathrm{a}} \\
\text { 3.3 Duration of surgery (including anesthesia) } \\
\text { 3.4 Recurrence rate }\end{array}$ \\
\hline $\begin{array}{l}\text { 4. In preterm infants, should hernia repair be performed before or after } \\
\text { hospital discharge or discharge from the Neonatal Intensive Care Unit (NICU)? }\end{array}$ & 4.1 Incarceration rate & $\begin{array}{l}\text { 4.2 Recurrence } \\
\text { 4.3 Reoperation rate } \\
\text { 4.4 Postoperative complications } \\
\text { 4.5 Respiratory difficulties } \\
\text { 4.6 Duration of surgery } \\
\text { 4.7 Length of hospital stay }\end{array}$ \\
\hline $\begin{array}{l}\text { 5. In preterm infants, is regional anesthesia associated with better } \\
\text { outcome compared to general anesthesia? }\end{array}$ & 5.1 Postoperative apnea's & $\begin{array}{l}\text { 5.2 Postoperative complications (bradycardia and } \\
\text { hypotension) } \\
\text { 5.3 Postoperative pain } \\
\text { 5.4 Failure of regional anesthesia } \\
\text { 5.5 Neurodevelopmental outcome at two years of age }\end{array}$ \\
\hline $\begin{array}{l}\text { 6. Should hernia repair in girls with irreducible ovary without symptoms of } \\
\text { incarceration or ischemia be performed as an emergency surgery? }\end{array}$ & 6.1 Ovarian complications ${ }^{b}$ & 6.2 Recurrence rate \\
\hline
\end{tabular}


Table 2. Oxford Centre for Evidence-Based Medicine 2011 Classification of levels of evidence and grades of recommendation (adapted from www.cebm.net).

\section{Level of evidence}

1. Systematic review of randomized trials or $n$-of -1 trials

2. Randomized trial or observational study

3. Non-randomized controlled cohort/follow-up study

4. Case-series, case-control studies or historically controlled studies

5. Mechanism-based reasoning (expert opinion)
Grade of Recommendation

A. Consistent Level 1 studies

B. Consistent Level 2 or 3 studies or extrapolation from Level 1 studies

C. Level 4 studies or extrapolations from Level 2 or 3 studies

D. Level 5 evidence or inconsistent or inconclusive studies of any level 
Table 3. Results of the meta-analysis for all outcomes for research question 1, 2, 4 and 5.

\begin{tabular}{|c|c|c|c|c|c|}
\hline Outcome measures & Patients (n) & OR $(95 \% \mathrm{Cl})$ & Mean difference $(95 \% \mathrm{Cl})$ & p-value & Favors \\
\hline \multicolumn{6}{|c|}{ Question 1. Is laparoscopic hernia repair (LH) associated with better outcome compared to open repair $(\mathrm{OH})$ ? } \\
\hline \multicolumn{6}{|c|}{\begin{tabular}{l|l|l} 
Primary & & \\
\end{tabular}} \\
\hline 1.1 Complications: intraoperative & 419 & $3.16(0.34$ to 29.60$)$ & N/A & 0.31 & - \\
\hline 1.1 Complications: postoperative & 622 & $0.37(0.10$ to 1.32$)$ & N/A & 0.13 & - \\
\hline 1.2 Recurrence rate & 693 & $0.88(0.20$ to 3.88$)$ & $\mathrm{N} / \mathrm{A}$ & 0.87 & - \\
\hline \multicolumn{6}{|l|}{ Secondary } \\
\hline 1.3 Incidence of $\mathrm{MClH}$ & 343 & $0.28(0.04$ to 1.86$)$ & N/A & 0.19 & - \\
\hline 1.4 Operation time (unilateral), $\mathrm{min}$ & 434 & N/A & $0.62(-5.70$ to 6.95$)$ & 0.85 & - \\
\hline 1.4 Operation time (bilateral), $\min$ & 194 & $\mathrm{~N} / \mathrm{A}$ & $-7.19(-10.04$ to -4.34$)$ & $<0.001$ & $\mathrm{LH}$ \\
\hline 1.5 Length of hospital stay, $h$ & 565 & $\mathrm{~N} / \mathrm{A}$ & $0.74(-0.38$ to 1.87$)$ & 0.20 & - \\
\hline 1.6 Time to full recovery, $h$ & 272 & $\mathrm{~N} / \mathrm{A}$ & $2.05(-11.13$ to 15.23$)$ & 0.76 & - \\
\hline \multicolumn{6}{|c|}{ Question 2. Which laparoscopic technique is associated with better outcome: the extra-peritoneal approach (EPA) or trans-peritoneal approach (TPA)? } \\
\hline \multicolumn{6}{|c|}{\begin{tabular}{l|l|l|l} 
Primary & & & \\
\end{tabular}} \\
\hline 2.1 Recurrence rate & 833 & $1.22(0.33$ to 4.47$)$ & N/A & 0.77 & - \\
\hline \multicolumn{6}{|l|}{ Secondary } \\
\hline 2.2 Operation time (unilateral), $\min$ & 93 & N/A & $-13.54(-16.08$ to -11.01$)$ & $<0.001$ & EPA \\
\hline 2.2 Operation time (bilateral), $\min$ & 740 & N/A & $-9.84(-16.66$ to -3.03$)$ & 0.005 & EPA \\
\hline 2.3 Conversion to open surgery & 833 & $2.88(0.29$ to 28.28$)$ & N/A & 0.36 & - \\
\hline 2.4 Complications: intraoperative vessel injury & 833 & 0.55 (0.09 to 3.38$)$ & $\mathrm{N} / \mathrm{A}$ & 0.52 & - \\
\hline 2.4 Complications: postoperative wound infection & 833 & $3.29(0.17$ to 64.65$)$ & $\mathrm{N} / \mathrm{A}$ & 0.43 & - \\
\hline 2.4 Complications: postoperative hydrocele & 833 & $1.04(0.32$ to 3.30$)$ & N/A & 0.95 & - \\
\hline 2.4 Complications: postoperative testicular atrophy & 833 & $0.15(0.01$ to 3.76$)$ & N/A & 0.25 & - \\
\hline \multicolumn{6}{|c|}{ Question 4. In preterm infants, should hernia repair be performed before (early) or after (late) hospital discharge/discharge from the Neonatal Intensive Care Unit (NICU)? } \\
\hline \multicolumn{6}{|c|}{\begin{tabular}{|l|l|l|l|l|l|} 
Primary & & & &
\end{tabular}} \\
\hline 4.1 Incarceration rate & 604 & $1.42(0.87$ to 2.34$)$ & N/A & 0.16 & - \\
\hline \multicolumn{6}{|l|}{ Secondary } \\
\hline 4.2 Recurrence rate & 519 & 3.52 (1.28 to 9.70$)$ & N/A & 0.01 & Late \\
\hline 4.3 Reoperation rate & 1468 & 1.60 (0.91 to 2.82$)$ & N/A & 0.10 & - \\
\hline 4.4 Postoperative complications: testicular atrophy & 165 & $\mathrm{~N} / \mathrm{A}$ & $\mathrm{N} / \mathrm{A}$ & $\mathrm{N} / \mathrm{A}$ & \\
\hline 4.4 Respiratory difficulties & 1930 & 4.90 (2.69 to 8.93$)$ & $\mathrm{N} / \mathrm{A}$ & $<0.001$ & Late \\
\hline
\end{tabular}




\begin{tabular}{|c|c|c|c|c|c|}
\hline \multicolumn{6}{|c|}{ Question 5. In preterm infants, is regional anesthesia associated with better outcome compared to general anesthesia? } \\
\hline \multicolumn{6}{|c|}{\begin{tabular}{l|l|l|} 
Primary & & \\
\end{tabular}} \\
\hline 5.1 Postoperative apnea's (overall) & 571 & $0.68(0.37$ to 1.23$)$ & N/A & 0.20 & - \\
\hline 5.1 Postoperative apnea ${ }^{\text {a }}$ & 541 & $0.46(0.22$ to 0.96$)$ & N/A & 0.04 & Regional \\
\hline 5.1 Postoperative apnea within the first postoperative hour & 465 & 0.60 (0.18 to 1.98$)$ & N/A & 0.41 & - \\
\hline 5.1 Postoperative apnea in infants with preoperative apnea's & 32 & 0.52 (0.11 to 2.45$)$ & N/A & 0.32 & - \\
\hline 5.1 Postoperative apnea requiring intervention & 470 & $0.11(0.00$ to 2.51$)$ & N/A & 0.17 & - \\
\hline 5.2 Postoperative complications: bradycardia & 135 & $0.75(0.29$ to 1.90$)$ & N/A & 0.54 & - \\
\hline 5.2 Postoperative complications: hypotension & 749 & 0.83 (0.01 to 95.94$)$ & N/A & 0.94 & - \\
\hline 5.3 Postoperative pain & 781 & $0.44(0.31$ to 0.63$)$ & $\mathrm{N} / \mathrm{A}$ & $<0.001$ & Regional \\
\hline
\end{tabular}


Table 4. Outcome results for question 3: should contralateral exploration be performed at the time of unilateral hernia repair or not?

\begin{tabular}{|c|c|c|c|}
\hline & Patients $n$ & Weighted average \% & $95 \% \mathrm{Cl}$ \\
\hline \multicolumn{4}{|c|}{ Intervention group (unilateral hernia repair with contralateral exploration) } \\
\hline Positive contralateral exploration (i.e. PPV) & 5726 & 63.49 & $56.88,69.86$ \\
\hline Complications & 3230 & $1.97^{\mathrm{a}}$ & $0.98,3.29$ \\
\hline Duration of surgery, $\min$ & - & - & - \\
\hline \multicolumn{4}{|c|}{ Control group (unilateral hernia repair without contralateral exploration) } \\
\hline Development of $\mathrm{MClH}$ after unilateral hernia repair & 3008 & 8.41 & $5.48,11.90$ \\
\hline Complications & 30 & 16.67 & NA \\
\hline Duration of surgery, $\min$ & - & - & - \\
\hline
\end{tabular}




\section{Outcomes}

1. Primary

- Operative and post-operative complications

- Recurrence rate

2. Secondary

- $\mathrm{MClH}$

- Duration of surgery (both operation and anesthesia)

- Duration of hospital admission (time to full recovery)

- Postoperative pain

\section{Search strategy}

\section{Pubmed:}

("hernia, inguinal"[MeSH] OR (("hernia"[tw] OR "hernias"[tw]) OR “herniorrhaphy“[tw] OR "herniotomy"[tw] AND "inguinal"[tw])) AND ("Child"[MeSH] OR "Child, preschool"[MeSH] OR "Young Adult"[MeSH] OR "Infant"[MeSH] OR "child"[tw] OR "children"[tw] OR "childhood"[tw] OR "schoolchild"[tw] OR "schoolchildren"[tw] OR "infant"[tw] OR "infants"[tw] OR "infancy"[tw] OR "boy"[tw] OR "boys"[tw] OR "boyhood"[tw] OR "girl"[tw] OR "girls"[tw] OR "girlhood"[tw] OR "youth"[tw] OR "youths"[tw] OR "toddler"[tw] OR "toddlers"[tw] OR "teen"[tw] OR "teens"[tw] OR "teenager"[tw] OR "Puberty"[Mesh] OR "puberty"[tw] OR "preschool"[tw] OR "pre school"[tiab] OR "pre-school"[tw] OR "juvenile"[tw] OR "young"[tw] OR "youngster"[tw] OR "youngsters"[tw] OR "schoolchild"[tw] OR "schoolchildren"[tw] OR "kid"[tw] OR "kids"[tw] OR "underage"[tw] OR "under age"[tw] OR "under aged"[tw] OR "puberal"[tw] OR "pubescent"[tw] OR "prepubescent"[tw] OR "prepuberty"[tw] OR "school age"[tw] OR "schoolage"[tw] OR "school ages"[tw] OR "Pediatrics"[Mesh] OR "Pediatrics"[tw] OR "Pediatric"[tw] OR "Paediatrics"[tw] OR "Paediatric"[tw]) AND ("laparoscopy"[MeSH] OR "laparoscopy"[tw] OR "laparoscopies"[tw] OR "laparoscopic"[tw] OR "minilaparoscopy"[tw] OR "minilaparoscopic"[tw]) AND ("Comparative Study" [Publication Type] OR compar*[tw] OR "open"[tw] OR "versus"[tw])

\section{Embase:}

(exp inguinal hernia/ OR (("hernia".mp. OR "hernias".mp.) OR "herniorrhaphy".mp. OR "herniotomy".mp. AND "inguinal".mp.)) AND (Exp Child/ OR exp young adult/ OR exp Infant/ OR "child".mp. OR "children".mp. OR "childhood".mp. OR "schoolchild".mp. OR "schoolchildren".mp. OR "infant".mp. OR "infants".mp. OR "infancy".mp. OR "boy".mp. OR "boys".mp. OR "boyhood".mp. OR "girl".mp. OR "girls".mp. OR "girlhood".mp. OR "youth".mp. OR "youths".mp. OR "toddler".mp. OR "toddlers".mp. OR "teen".mp. OR "teens".mp. OR "teenager".mp. OR exp Puberty/ OR "puberty".mp. OR "preschool".mp. OR "pre school".ti,ab. OR "pre-school".mp. OR "juvenile".mp. OR "young".mp. OR "youngster".mp. OR "youngsters".mp. OR "schoolchild".mp. OR "schoolchildren".mp. OR "kid".mp. OR "kids".mp. OR "underage".mp. OR "under age".mp. OR "under aged".mp. OR "puberal".mp. OR "pubescent".mp. OR "prepubescent".mp. OR "prepuberty".mp. OR "school age".mp. OR "schoolage".mp. OR "school ages".mp. OR exp Pediatrics/ OR "Pediatrics".mp. OR "Pediatric".mp. OR "Paediatrics".mp. OR "Paediatric".mp.) AND (exp laparoscopy/ OR "laparoscopy".mp. OR "laparoscopies".mp. OR "laparoscopic".mp. OR "minilaparoscopy".mp. OR 
"minilaparoscopic".mp.) AND (exp Comparative Study/ OR compar*.mp. OR "open".mp. OR "versus".mp.)

\section{Cochrane:}

(("hernia" OR "hernias" OR "herniorrhaphy" OR "herniotomy") AND "inguinal") AND ("Adolescent" OR "Young Adult" OR "Infant" OR "child" OR "children" OR "childhood" OR "schoolchild" OR "schoolchildren" OR "infant" OR "infants" OR "infancy" OR "boy" OR "boys" OR "boyhood" OR "girl" OR "girls" OR "girlhood" OR "youth" OR "youths" OR "toddler" OR "toddlers" OR "teen" OR "teens" OR "teenager" OR "Puberty" OR "puberty" OR "preschool" OR "pre school" OR "pre-school" OR "juvenile" OR "young" OR "youngster" OR "youngsters" OR "schoolchild" OR "schoolchildren" OR "kid" OR "kids" OR "underage" OR "under age" OR "under aged" OR "puberal" OR "pubescent" OR "prepubescent" OR "prepuberty" OR "school age" OR "schoolage" OR "school ages" OR "Pediatrics" OR "Pediatric" OR "Paediatrics" OR "Paediatric") AND ("laparoscopy" OR "laparoscopies" OR "laparoscopic" OR "minilaparoscopy" OR "minilaparoscopic") AND ("Comparative Study" OR compar* OR "open" OR "versus") 
Table 1. Risk of bias assessment in randomized controlled studies using ROB 2.0

\begin{tabular}{|c|c|c|c|c|c|c|c|c|}
\hline \multirow[t]{2}{*}{ Domains } & Chan et al. & Celebi et al. & Gause et al. & Koivusalo et al. & Saranga et al. & Shalaby et al. & Inal et al. & Zhu et al. \\
\hline & 01-06 & $01|02| 04 \mid 06$ & $01|02| 04-06$ & 01-06 & $01|02| 04$ & $01|02| 04 \mid 05$ & O4 & 01-05 \\
\hline $\begin{array}{l}\text { Bias arising from the randomization } \\
\text { process }\end{array}$ & Low & Low & Low & Low & High & Low & Unclear & Low \\
\hline $\begin{array}{l}\text { Bias due to deviations from intended } \\
\text { interventions }\end{array}$ & Low & Low & Low & Low & Unclear & Unclear & Unclear & Unclear \\
\hline Bias due to missing outcome data & Low & Low & Low & Low & Low & Low & Low & Low \\
\hline Bias in measurement of the outcome & Low & Low & Low & Low & Unclear & Unclear & Unclear & Unclear \\
\hline $\begin{array}{l}\text { Bias in selection of the reported result } \\
\text { Overall }\end{array}$ & $\begin{array}{l}\text { Unclear } \\
\text { Low }\end{array}$ & $\begin{array}{l}\text { Unclear } \\
\text { Low }\end{array}$ & $\begin{array}{l}\text { Unclear } \\
\text { Low }\end{array}$ & $\begin{array}{l}\text { Unclear } \\
\text { Low }\end{array}$ & $\begin{array}{l}\text { Unclear } \\
\text { Some concerns }\end{array}$ & $\begin{array}{l}\text { Unclear } \\
\text { Low }\end{array}$ & $\begin{array}{l}\text { Unclear } \\
\text { Low }\end{array}$ & $\begin{array}{l}\text { Unclear } \\
\text { Low }\end{array}$ \\
\hline
\end{tabular}

The risk of bias is scored as "low", "some concerns", or "high"

01 outcome 1 (complications), 02 outcome 2 (recurrence rate), 03 outcome 3 (incidence of metachronous contralateral inguinal hernia), 04 outcome 4 (duration of surgery (including anesthesia)), 05 outcome 5 (length of hospital stay), 06 outcome 6 (time to full recovery) 
Table 2 Risk of bias assessment in non-randomized studies using ROBINS-I

\begin{tabular}{|c|c|c|c|}
\hline \multirow[t]{2}{*}{ Domain } & Bharathi et al. & Korkmaz et al. & Wang et al. \\
\hline & $01-07$ & 01-07 & 01-07 \\
\hline Bias due to confounding & Serious & Serious & Serious \\
\hline Bias in selection of participants into the study & Low & Low & Low \\
\hline Bias in classification of interventions & Low & Low & Low \\
\hline Bias due to deviations from intended interventions & Low & Low & Low \\
\hline Bias due to missing data & Low & Low & Low \\
\hline Bias in measurement of outcomes & Low & Low & Low \\
\hline Bias in selection of the reported result & Low & Low & Low \\
\hline Overall & Serious & Serious & Serious \\
\hline
\end{tabular}

01 outcome 1 (postoperative hernial recurrence), 02 outcome 2 (intra-operative vessel injury), 03 outcome 3 (intra-operative conversion to open), 04 outcome 4 (postoperative hydrocele), O5 outcome 5 (Postoperative testicular atrophy), 06 outcome 6 (postoperative wound infection), 07 outcome 7 (operation time (bilateral \& unilateral))

\section{Table 3 Risk of bias assessment in the randomized controlled study using ROB 2.0}

\begin{tabular}{lc}
\hline Domain & Shalaby et al. \\
\cline { 2 - 2 } & O1-07 \\
\hline Bias arising from the randomization process & Low \\
Bias due to deviations from intended interventions & Low \\
Bias due to missing outcome data & Low \\
Bias in measurement of the outcome & Low \\
Bias in selection of the reported result & Low \\
Overall & Low \\
\hline The risk of bias is scored as "low", "some concerns", or "high"
\end{tabular}

01 outcome 1 (postoperative hernial recurrence), 02 outcome 2 (intra-operative vessel injury), 03 outcome 3 (intra-operative conversion to open), 04 outcome 4 (postoperative hydrocele), O5 outcome 5 (Postoperative testicular atrophy), 06 outcome 6 (postoperative wound infection), 07 outcome7 (operation time (bilateral)) 
Question 3. Should contralateral inguinal exploration be performed at the time of open unilateral inguinal hernia repair?

\section{Table 4 Risk of bias assessment in non-randomized studies using ROBINS-I}

\begin{tabular}{|c|c|c|c|c|c|c|c|c|c|c|}
\hline \multirow[t]{2}{*}{ Domain } & \multirow{2}{*}{$\begin{array}{c}\begin{array}{c}\text { Clausen et } \\
\text { al. }\end{array} \\
01\end{array}$} & \multirow{2}{*}{$\begin{array}{c}\text { Disma et al. } \\
01\end{array}$} & \multirow{2}{*}{$\begin{array}{c}\text { Gilbert et } \\
\text { al. } \\
\text { O3 }\end{array}$} & \multicolumn{2}{|c|}{$\begin{array}{l}\text { Gunnlaugsson et } \\
\text { al. }\end{array}$} & \multirow{2}{*}{$\begin{array}{c}\text { Holcomb et } \\
\text { al. } \\
01-03\end{array}$} & \multirow{2}{*}{$\begin{array}{c}\begin{array}{c}\text { Jona et al. } \\
\text { (II) }\end{array} \\
01|02| 04\end{array}$} & \multirow{2}{*}{$\begin{array}{l}\text { Kalani et al. } \\
01|02| 04\end{array}$} & \multirow{2}{*}{$\begin{array}{c}\text { Kling et al. } \\
\mathrm{O} 1\end{array}$} & \multirow{2}{*}{$\begin{array}{c}\text { Laufer et } \\
\text { al. } \\
\text { O2 }\end{array}$} \\
\hline & & & & 01-03 & 04 & & & & & \\
\hline Bias due to confounding & Serious & Moderate & Serious & Serious & Serious & Serious & Moderate & Serious & Critical & Serious \\
\hline Bias in selection of participants into the study & Low & Low & Low & Low & Low & Low & Low & Low & Low & Low \\
\hline Bias in classification of interventions & Low & Low & Low & Low & Low & Low & Low & Low & Low & Low \\
\hline $\begin{array}{l}\text { Bias due to deviations from intended } \\
\text { interventions }\end{array}$ & Low & Low & Low & Low & Low & Low & Low & Low & Low & Low \\
\hline Bias due to missing data & $\mathrm{NI}$ & Low & $\mathrm{NI}$ & $\mathrm{NI}$ & $\mathrm{NI}$ & $\mathrm{NI}$ & $\mathrm{NI}$ & $\mathrm{NI}$ & $\mathrm{NI}$ & $\mathrm{NI}$ \\
\hline Bias in measurement of outcomes & Low & Low & Low & Serious & Serious & Low & Serious & Low & Low & Low \\
\hline Bias in selection of the reported result & $\mathrm{NI}$ & Low & $\mathrm{NI}$ & $\mathrm{NI}$ & $\mathrm{NI}$ & $\mathrm{NI}$ & $\mathrm{NI}$ & $\mathrm{NI}$ & $\mathrm{NI}$ & $\mathrm{NI}$ \\
\hline Overall & Serious & Moderate & Serious & Serious & Serious & Serious & Serious & Serious & Critical & Serious \\
\hline
\end{tabular}

The risk of bias is scored as "low", "moderate", "serious", "critical" or "NI: no information"

B.

\begin{tabular}{|c|c|c|c|c|c|c|c|c|}
\hline \multirow[t]{2}{*}{ Domain } & $\begin{array}{c}\text { Lugo Vincente et } \\
\text { al. }\end{array}$ & Maillet et al. & $\begin{array}{c}\text { Martin et } \\
\text { al. }\end{array}$ & $\begin{array}{l}\text { McLaughlin et } \\
\text { al. }\end{array}$ & $\begin{array}{c}\text { Moss et } \\
\text { al. }\end{array}$ & Rescorla et al. & $\begin{array}{c}\text { Rothenberg et } \\
\text { al. }\end{array}$ & $\begin{array}{c}\text { Simpson et } \\
\text { al. }\end{array}$ \\
\hline & $02-04$ & $01|02| 04$ & $\mathrm{O} 3$ & 01-04 & $\mathrm{O} 2$ & $01|02| 04$ & $\mathrm{O} 2$ & $\mathrm{O} 2-\mathrm{O} 4$ \\
\hline Bias due to confounding & Moderate & Serious & Serious & Critical & Serious & Serious & Serious & Serious \\
\hline Bias in selection of participants into the study & Low & Low & Moderate & Moderate & Low & Low & Low & Moderate \\
\hline Bias in classification of interventions & Low & Low & Low & Low & Low & Low & Low & Low \\
\hline Bias due to deviations from intended interventions & Low & Low & Low & Low & Low & Low & Low & Low \\
\hline Bias due to missing data & $\mathrm{NI}$ & $\mathrm{NI}$ & $\mathrm{NI}$ & $\mathrm{NI}$ & $\mathrm{NI}$ & $\mathrm{NI}$ & $\mathrm{NI}$ & $\mathrm{NI}$ \\
\hline Bias in measurement of outcomes & Low & Low & $\mathrm{NI}$ & $\mathrm{NI}$ & Serious & Serious & Low & Serious \\
\hline Bias in selection of the reported result & $\mathrm{NI}$ & Low & $\mathrm{NI}$ & $\mathrm{NI}$ & $\mathrm{NI}$ & $\mathrm{NI}$ & $\mathrm{NI}$ & $\mathrm{NI}$ \\
\hline Overall & NI & Serious & Serious & Critical & Serious & Serious & serious & Serious \\
\hline
\end{tabular}

The risk of bias is scored as "low", "moderate", "serious", "critical" or "NI: no information" 


\begin{tabular}{|c|c|c|c|c|c|}
\hline \multirow[t]{2}{*}{ Domain } & Solomon et al. & Surana et al. & Tepas et al. & Wright et al. & Zampieri et al. \\
\hline & $\mathrm{O} 2$ & 01 & 01 & 01 & $02 \mid 04$ \\
\hline Bias due to confounding & Serious & Serious & Critical & Critical & Serious \\
\hline Bias in selection of participants into the study & Low & Moderate & Low & Low & Serious \\
\hline Bias in classification of interventions & Low & Low & Low & Low & Low \\
\hline Bias due to deviations from intended interventions & Low & Low & Low & Low & Low \\
\hline Bias due to missing data & $\mathrm{NI}$ & $\mathrm{NI}$ & $\mathrm{NI}$ & $\mathrm{NI}$ & $\mathrm{NI}$ \\
\hline Bias in measurement of outcomes & Low & Serious & Low & Low & Low \\
\hline Bias in selection of the reported result & $\mathrm{NI}$ & $\mathrm{NI}$ & $\mathrm{NI}$ & $\mathrm{NI}$ & $\mathrm{NI}$ \\
\hline Overall & Serious & Serious & Critical & Critical & Serious \\
\hline
\end{tabular}

The risk of bias is scored as "low", "moderate", "serious", "critical" or "NI: no information"

O1 outcome 1 (incidence of metachronous contralateral inguinal hernia), O2 outcome 2 (complications), O3 outcome 3 (duration of surgery), O4 outcome 4 (recurrence rate) 
Table 5 Risk of bias assessment in non-randomized studies using ROBINS-I

\begin{tabular}{|c|c|c|c|c|c|c|c|c|c|c|}
\hline \multirow[t]{2}{*}{ Domain } & \multicolumn{2}{|c|}{ Crankson et al. 2015} & \multicolumn{2}{|c|}{ Khan et al. 2018} & \multirow{2}{*}{$\begin{array}{c}\text { Lee et al. } \\
2011 \\
01 \mid 03\end{array}$} & \multirow{2}{*}{$\begin{array}{c}\text { Pandey et al. } \\
2016 \\
01-03\end{array}$} & \multirow{2}{*}{$\begin{array}{c}\begin{array}{c}\text { Sulkowski et } \\
\text { al. } 2015\end{array} \\
01-03\end{array}$} & \multirow{2}{*}{$\begin{array}{c}\begin{array}{c}\text { Takahashi et } \\
\text { al. } 2012\end{array} \\
\text { 01-03 }\end{array}$} & \multicolumn{2}{|c|}{ Young et al. 2018} \\
\hline & 01-02 & 03 & O1-02 & O3 & & & & & O1-02 & 03 \\
\hline Bias due to confounding & Serious & Serious & Serious & Serious & Serious & Serious & Serious & Serious & Serious & NA \\
\hline $\begin{array}{l}\text { Bias in selection of participants } \\
\text { into the study }\end{array}$ & Moderate & Moderate & Moderate & Moderate & Moderate & Moderate & Moderate & Moderate & Moderate & NA \\
\hline $\begin{array}{l}\text { Bias in classification of } \\
\text { interventions }\end{array}$ & Moderate & Moderate & Moderate & Moderate & Moderate & Moderate & Moderate & Moderate & Moderate & NA \\
\hline $\begin{array}{l}\text { Bias due to deviations from } \\
\text { intended interventions }\end{array}$ & Low & Moderate & Moderate & Moderate & Low & Low & Moderate & Low & Low & NA \\
\hline Bias due to missing data & Low & Low & Low & Low & Low & Low & Moderate & Low & Low & NA \\
\hline Bias in measurement of outcomes & Moderate & Serious & Moderate & Serious & Moderate & Moderate & Moderate & Moderate & Moderate & NA \\
\hline $\begin{array}{l}\text { Bias in selection of the reported } \\
\text { result }\end{array}$ & Moderate & Moderate & Moderate & Moderate & Moderate & Moderate & Moderate & Moderate & Moderate & NA \\
\hline Overall & Serious & Serious & Serious & Serious & Serious & Serious & Serious & Serious & Serious & NA \\
\hline
\end{tabular}

The risk of bias is scored as "low", "moderate", "serious", "critical" or "NI: no information"

O1 outcome 1 (incarceration rate), 02 outcome 2 (recurrence rate/reoperation rate), 03 outcome 3 (respiratory difficulties) 


\section{Question 5. In preterm infants, is regional anesthesia associated with better outcome compared to general anesthesia?}

Table 6. Risk of bias assessment in randomized controlled studies using ROB 2.0

\begin{tabular}{|c|c|c|c|c|c|c|c|c|}
\hline \multirow[t]{2}{*}{ Domain } & $\begin{array}{l}\text { Welborn et al. } \\
1990\end{array}$ & $\begin{array}{c}\text { Krane et al. } \\
1995\end{array}$ & $\begin{array}{c}\text { Somri et al. } \\
1998\end{array}$ & $\begin{array}{c}\text { Kunst et al. } \\
1999\end{array}$ & $\begin{array}{l}\text { Williams et al. } \\
2001\end{array}$ & $\begin{array}{l}\text { El-Gohari et al. } \\
2004\end{array}$ & Das et al. 2005 & $\begin{array}{l}\text { GAS trials } \\
2015-2019\end{array}$ \\
\hline & $01-2$ & $02-3$ & 01-4 & $01-2$ & $01|02| 04$ & $01 \mid 04$ & $01|03| 04$ & $01-5$ \\
\hline $\begin{array}{l}\text { Bias arising from the randomization } \\
\text { process }\end{array}$ & High & High & High & Some concerns & Some concerns & High & Low & Low \\
\hline $\begin{array}{l}\text { Bias due to deviations from intended } \\
\text { interventions }\end{array}$ & Some concerns & $\mathrm{NI}$ & $\mathrm{NI}$ & $\mathrm{NI}$ & Some concerns & Some concerns & Low & Low \\
\hline Bias due to missing outcome data & Low & Low & High & Low & High & High & Low & Low \\
\hline Bias in measurement of the outcome & Low & Low & Some concerns & High & Some concerns & High & Some concerns & Low \\
\hline Bias in selection of the reported result & Some concerns & Some concerns & High & High & Some concerns & $\mathrm{NI}$ & Some concerns & Low \\
\hline Overall & Some concerns & Some concerns & High & High & Some concerns & High & Some concerns & Low \\
\hline
\end{tabular}

The risk of bias is scored as "low", "some concerns", "high" or "NI": no information

O1 outcome 1 (Postoperative apneas), 02 outcome 2 (Postoperative complications : bradycardia/hypotension), O3 outcome 3 (Postoperative pain), 04 outcome 4 (Incidence of failure of regional analgesia), 05 outcome 5 (Neurodevelopmental outcome at 2 years of age). 
Table 7. Risk of bias assessment in non-randomized studies using ROBINS-I

\begin{tabular}{|c|c|c|c|c|c|c|c|c|c|c|c|c|}
\hline Domain & $\begin{array}{l}\text { Boley et } \\
\text { al. }\end{array}$ & $\begin{array}{l}\text { Stylianos } \\
\text { et al. }\end{array}$ & $\begin{array}{l}\text { Merriman } \\
\text { et al. }\end{array}$ & $\begin{array}{l}\text { Huang et } \\
\text { al. }\end{array}$ & $\begin{array}{c}\text { Takehara et } \\
\text { al. }\end{array}$ & $\begin{array}{l}\text { Houben et } \\
\text { al. }\end{array}$ & $\begin{array}{l}\text { Hirabayashi } \\
\text { et al. }\end{array}$ & Lee et al. & $\begin{array}{l}\text { Chen et } \\
\text { al. }\end{array}$ & $\begin{array}{l}\text { Esposito } \\
\text { et al. }\end{array}$ & $\begin{array}{l}\text { Marinkovic } \\
\text { et al. }\end{array}$ & Turk et al. \\
\hline & 01 & 01 & 01 & 01 & 01 & 01102 & 01 & 01102 & 01 & 01102 & 01 & 01 \\
\hline $\begin{array}{l}\text { Bias arising from the } \\
\text { randomization } \\
\text { process }\end{array}$ & Serious & Serious & Serious & Serious & Serious & Serious & Serious & Serious & Serious & Moderate & Moderate & Moderate \\
\hline $\begin{array}{l}\text { Bias due to deviations } \\
\text { from intended } \\
\text { interventions }\end{array}$ & Low & Low & Low & Low & Low & Low & Low & Low & Low & Low & Low & Low \\
\hline $\begin{array}{l}\text { Bias due to missing } \\
\text { outcome data }\end{array}$ & moderate & Serious & Moderate & Moderate & Moderate & Low & Low & Low & Low & Low & Serious & $\mathrm{NI}$ \\
\hline $\begin{array}{l}\text { Bias in measurement } \\
\text { of the outcome }\end{array}$ & Low & Serious & Moderate & Moderate & Low & Low & Low & Moderate & Moderate & Low & Serious & $\mathrm{NI}$ \\
\hline $\begin{array}{l}\text { Bias in selection of the } \\
\text { reported result }\end{array}$ & $\mathrm{NI}$ & $\mathrm{NI}$ & $\mathrm{NI}$ & $\mathrm{NI}$ & $\mathrm{Ni}$ & Moderate & Low & $\mathrm{NI}$ & Low & Low & $\mathrm{NI}$ & Moderate \\
\hline Overall & Serious & Serious & Serious & Serious & Serious & Serious & Serious & Serious & Serious & Moderate & Serious & Serious \\
\hline
\end{tabular}

The risk of bias is scored as "low", "moderate", "serious", "critical" or "Nl: no information"

O1 outcome 1 (complications); O2 outcome 2 (recurrence rate) 
Table 1. Study characteristics and patient demographics of studies comparing laparoscopic and open hernia repair in children (review question 1).

Table 2. Table 1. Study characteristics and patient demographics of studies comparing extra-peritoneal (EPA) versus trans-peritoneal (TPA) laparoscopic hernia repair in children (review question 2).

\begin{tabular}{|c|c|c|c|c|c|c|c|c|c|c|c|}
\hline & & & & & & & Late & ality & App & pach & \\
\hline Author & Year & Country & Study design & Patients, $n$ & Male, $n(\%)$ & Age range & Unilateral, $n$ & Bilateral, $n$ & $\begin{array}{l}\text { EPA, } n \\
(\%)\end{array}$ & $\begin{array}{l}\text { TPA, } n \\
\text { (\%) }\end{array}$ & $\begin{array}{l}\text { Follow-up, } \\
\text { mean }\end{array}$ \\
\hline Bharati et al. & 2008 & India & Retrospective cohort & 163 & $143(87.7)$ & $1-14 \mathrm{yr}$ & 146 & 17 & $112(68.7)$ & $51(31.3)$ & $3 \mathrm{mo}$ \\
\hline Shalaby et al. & 2010 & Egypt & RCT & 150 & $120(80)$ & $2-96 \mathrm{mo}$ & Unclear & Unclear & $75(50)$ & $75(50)$ & $24 \mathrm{mo}$ \\
\hline Korkmaz et al. & 2018 & Turkey & Retrospective cohort & 71 & $31(43.7)$ & $3.5-60 \mathrm{mo}$ & 64 & 7 & $24(33.8)$ & $47(66.2)$ & - \\
\hline Wang et al. & 2019 & China & Retrospective cohort & 599 & $533(89)$ & $40.5 \pm 31.6 \mathrm{mo}$ & 530 & 69 & $412(68.8)$ & $187(31.2)$ & $26 \mathrm{mo}$ \\
\hline
\end{tabular}

Table 3. Study characteristics, patient demographics and hernia characteristics of patients with unilateral inguinal hernia who underwent contralateral inguinal exploration or not (i.e. control group)(review question 3).

\begin{tabular}{|c|c|c|c|c|c|c|c|c|c|}
\hline Study & Year & Study design & Patients, $n$ & Male, $n(\%)$ & Age range & $\begin{array}{l}\text { Positive CE, } \\
n(\%)\end{array}$ & $\begin{array}{l}\text { Control } \\
\text { group, } n^{\text {a }}\end{array}$ & $\begin{array}{l}\text { Development } \\
\text { of } \mathrm{MCIH}, n(\%)\end{array}$ & $\begin{array}{l}\text { Follow-up, } \\
\text { mean (range) }\end{array}$ \\
\hline Rothenberg et al. & 1955 & Retrospective cohort & 50 & $3(6)$ & $1 \mathrm{mo}-12 \mathrm{yr}$ & $37(74)$ & - & - & - \\
\hline Clausen et al. & 1958 & Retrospective cohort & 164 & Unclear & $0-2 y r,>2 y r$ & $79(48.2)$ & 708 & $36(7.6)$ & $3 y r$ \\
\hline McLaughlin et al. & 1960 & Retrospective cohort & 108 & Unclear & $0-3 \mathrm{yr}$ & $60(55.6)$ & - & - & - \\
\hline Gilbert et al. & 1960 & Prospective cohort & 100 & $13(13)$ & $0-4 \mathrm{yr},>4 \mathrm{yr}$ & $59(59)$ & - & - & - \\
\hline Laufer et al. & 1961 & Prospective cohort & 120 & $16(13.3)$ & $0-9 \mathrm{yr}$ & $76(63.4)$ & - & - & - \\
\hline Martin et al. & 1961 & Prospective cohort & 55 & $10(18.2)$ & $1 \mathrm{mo}-12 \mathrm{yr}$ & $46(83.6)$ & - & - & - \\
\hline Kling et al. & 1963 & Retrospective cohort & 33 & $1(3)$ & $0-10 \mathrm{yr}$ & $22(66.6)$ & 530 & $54(10.1)$ & $>4 \mathrm{yr}$ \\
\hline Holcomb et al. & 1965 & Prospective cohort & 433 & $62(14.3)$ & $10 \mathrm{~h}-12 \mathrm{yr}$ & $242(56)$ & - & - & - \\
\hline Solomon et al. & 1967 & Prospective cohort & 100 & $13(13)$ & $0-14 \mathrm{yr}$ & $40(40)$ & - & - & - \\
\hline Gunnlaugsson et al. & 1967 & Retrospective cohort & 174 & Unclear & $0-15 \mathrm{yr}$ & $153(88)$ & 11 & $2(18)$ & - \\
\hline Simpson et al. & 1968 & Retrospective cohort & 218 & Unclear & $0-15 \mathrm{yr}$ & $188(86)$ & - & - & - \\
\hline Rowe et al. & 1969 & Retrospective cohort & 1,965 & Unclear & $0-16 \mathrm{yr}$ & $946(48)$ & - & - & - \\
\hline
\end{tabular}




\begin{tabular}{|c|c|c|c|c|c|c|c|c|c|}
\hline Kalani et al. & 1972 & Prospective cohort & 100 & Unclear & $0-10 \mathrm{yr}$ & $61(61)$ & 30 & $3(10)$ & $3 y r$ \\
\hline Wright et al. & 1982 & Retro- and prospective cohort & 100 & $100(100)$ & $0-12 y r$ & $39(39)$ & 8 & $2(25)$ & - \\
\hline Resclorla et al. & 1984 & Retrospective cohort & 92 & $85 / 100^{*}$ & $0-2 \mathrm{mo}$ & $81(88)$ & 8 & $3(37.5)$ & - \\
\hline Tepas et al. & 1985 & Prospective cohort & 121 & $0(0)$ & $0-6 \mathrm{mo}$ & $75(61)$ & $179^{\mathrm{b}}$ & $2(1.1)$ & $3-6 y r$ \\
\hline Moss et al. & 1991 & Retrospective cohort & 300 & Unclear & $0-2 \mathrm{mo}$ & $255(85)$ & - & - & $27 \mathrm{mo}$ \\
\hline Surana et al. & 1992 & Retrospective cohort & 390 & $53(13.6)$ & $0-2 y r$ & $191(49)$ & 551 & $54(9.8)$ & - \\
\hline Gupta et al. & 1993 & Retrospective cohort & 9 & $7(77.8)$ & $0-12 \mathrm{yr}$ & Unclear & - & - & - \\
\hline Lugo Vincente et al. & 1995 & Retrospective cohort & 116 & $89 / 161^{*}$ & $0-6 \mathrm{yr},>6 \mathrm{yr}$ & $85(73)$ & - & - & $6 \mathrm{yr}$ \\
\hline \multirow[t]{2}{*}{ Jona et al. } & 1996 & Retrospective cohort & 320 & $252(78.8)$ & $3 w k-6 y r$ & Unclear & - & - & - \\
\hline & & Prospective cohort & 331 & $265(80.1)$ & $<6 \mathrm{yr}$ & $183(55)$ & 41 & $6(14)$ & $10 \mathrm{yr}$ \\
\hline Zampieri et al. & 2008 & Retrospective cohort & 118 & $0(0)$ & $1 \mathrm{mo}-8 \mathrm{yr}$ & $56(47.5)$ & - & - & $3 \mathrm{mo}$ \\
\hline Maillet et al. & 2014 & Retrospective cohort & 407 & $407(100)$ & $12 d y-492 d y$ & $204(50.1)$ & 575 & $60(11)$ & $12 \mathrm{mo}$ \\
\hline Disma et al. & 2018 & RCT with cohort & 131 & Unclear & Unclear & $90(68.9)$ & 367 & $10(2.7)$ & $24 \mathrm{mo}$ \\
\hline \multicolumn{10}{|c|}{ CE, contralateral exploration; RCT, randomized controlled trial; dy, day; wk, weeks; mo, months; yr, year } \\
\hline \multicolumn{10}{|c|}{${ }^{a}$ Control group existed of patients who only underwent unilateral inguinal hernia repair without contralateral exploration } \\
\hline \multicolumn{10}{|c|}{${ }^{\mathrm{b}}$ Patients in the unilateral hernia repair group were all male aged between 6-24 months } \\
\hline
\end{tabular}

Table 4. Study characteristics, patient demographics and hernia characteristics of preterm infants undergoing hernia repair before and after discharge from the hospital or neonatal intensive care unit (NICU)(review question 4).

\begin{tabular}{|c|c|c|c|c|c|c|c|c|c|}
\hline & & & & & Timing & f surgery & & & Laterality, \% \\
\hline Author & Year & Country & Study design & Patients, $n$ & $\begin{array}{l}\text { Before } \\
\text { discharge }\end{array}$ & \begin{tabular}{|l|} 
After \\
discharge
\end{tabular} & Male, $n(\%)$ & $\begin{array}{l}\text { PCA at surgery, mean } \\
\text { (SD) / (range), weeks }\end{array}$ & $\begin{array}{l}\text { Right, left, bilatera } \\
\text { hernia }\end{array}$ \\
\hline Crankson et al. & 2015 & Saudi Arabia & Retrospective cohort & 84 & 23 & 61 & $74(88)$ & $\begin{array}{l}\text { B: } 39.5 \pm 3.1 \\
\text { A: } 62.9 \pm 32.6\end{array}$ & $\begin{array}{l}\text { B: } 40.1,30.4,30.4 \\
\text { A: } 39.3,31.1,29.5\end{array}$ \\
\hline Khan et al. & 2018 & USA & Retrospective cohort & 263 & 115 & 148 & $\begin{array}{l}\text { (male : female) } \\
3.3: 1\end{array}$ & $\begin{array}{l}\text { B: } 39.5(4) \\
\text { A: } 40.8(7.4)\end{array}$ & Unclear \\
\hline Lee et al. & 2011 & USA & Retrospective cohort & 80 & 45 & 35 & $65(81 \%)$ & $\begin{array}{l}\text { B: } 37.0 \pm 6.7 \\
\text { A: } 44.1 \pm 7.9\end{array}$ & $85 \%$ bilateral \\
\hline Pandey et al. & 2017 & USA & Retrospective cohort & 39 & 23 & 16 & $\begin{array}{l}\text { B: } 17(74) \\
\text { A: } 11(69)\end{array}$ & $\begin{array}{l}\text { B: } 41.6 \pm 3.9 \\
\text { A: } 45.4 \pm 4.6\end{array}$ & $\begin{array}{l}\text { B: } 13,8.6,78.3 \\
\text { A: } 31.3,25,43.7\end{array}$ \\
\hline Sulkowski et al. & 2015 & USA & Retrospective cohort & 1,421 & 938 & 483 & $\begin{array}{l}\text { B: } 776(82.7) \\
\text { A: } 430(89)\end{array}$ & $\begin{array}{l}\text { B: } 38(36,41) \\
\text { A: } 49(43,55)\end{array}$ & Unclear \\
\hline
\end{tabular}




\begin{tabular}{|l|l|l|l|l|l|l|l|l|}
\hline Takahashi et al. & 2012 & Japan & Retrospective cohort & 47 & 14 & 33 & $\begin{array}{l}\text { B: } 7(50) \\
\text { A: } 21(64)\end{array}$ & $\begin{array}{l}\text { B: } 42.2 \pm 5.7 \\
\text { A: } 48.8 \pm 3.7\end{array}$ \\
\hline Youn et al. & 2018 & South Korea & Retrospective cohort & 90 & 18 & 72 & $\begin{array}{l}\text { B: } 13(82.2) \\
\text { A: } 59(81.9)\end{array}$ & \begin{tabular}{l}
$13(2.7-58)$ \\
\multicolumn{7}{|l|}{}
\end{tabular} \\
\hline
\end{tabular}


Table 5. Study characteristics and patient demographics of preterm infants undergoing hernia repair under general or regional anesthesia (review question 5).

\begin{tabular}{|c|c|c|c|c|c|c|c|c|}
\hline & & & & & Type o & lesthesia & & \\
\hline Author & Year & Country & Study design & Patients, $n$ & $\begin{array}{l}\text { Central } \\
\text { regional }\end{array}$ & General & $\begin{array}{l}\text { GA at birth } \\
\text { mean/median }(*) ; \\
\pm S D / \text { (range), weeks }\end{array}$ & $\begin{array}{l}\text { PCA at surgery, } \\
\text { mean/median }\left({ }^{*}\right) ; \\
\pm \text { SD / (range), weeks }\end{array}$ \\
\hline Welborn et al. & 1990 & USA & RCT & 36 & 20 & 16 & $\begin{array}{l}\text { C: } 31.4(25-36) \\
G: 31.8(25-36)\end{array}$ & $\begin{array}{l}\text { C: } 40.8(35-46) \\
G: 43.3(38-51)\end{array}$ \\
\hline Krane et al. & 1995 & USA & RCT & 18 & 9 & 9 & $\begin{array}{l}\text { C: } 29.2 \pm 3.6 \\
\text { G: } 29.9 \pm 3.9\end{array}$ & $\begin{array}{l}\text { C: } 42.3 \pm 4.1 \\
\text { G: } 40.9 \pm 2.1\end{array}$ \\
\hline Somri et al. & 1998 & Israel & RCT & 40 & 20 & 20 & $\begin{array}{l}\text { C: } 33.1 \pm 4.0 \\
\text { G: } 32.7 \pm 3.2\end{array}$ & $\begin{array}{l}\text { C: } 43.7 \pm 5.3 \\
\text { G: } 44.2 \pm 5.4\end{array}$ \\
\hline Kunst et al. & 1999 & Germany & RCT & 17 & 8 & 9 & $\begin{array}{l}\text { C: } 26.9 \pm 2.0 \\
\text { G: } 29.7 \pm 3.7\end{array}$ & \\
\hline Williams et al. & 2001 & UK & RCT & 24 & 10 & 14 & $\begin{array}{l}\text { C: } 28^{*}(26,33) \\
G: 30^{*}(23,35)\end{array}$ & $\begin{array}{l}\text { C: } 40^{*}(36,44) \\
G: 38^{*}(32-46)\end{array}$ \\
\hline El Gohari et al. & 2004 & Egypt & RCT & 30 & 15 & 15 & Not specified & Not specified \\
\hline Das et al. & 2005 & India & RCT & 30 & 15 & 15 & Not specified & Not specified \\
\hline GAS Study & 2015 & Multicenter & RCT & 711 & 355 & 356 & $\begin{array}{l}\text { C: } 35.5 \pm 4.1 \\
G: 35.5 \pm 3.9\end{array}$ & $\begin{array}{l}\text { C: } 45.5 \pm 4.7 \\
G: 45.6 \pm 4.6\end{array}$ \\
\hline
\end{tabular}


Table 6. Study characteristics, patient demographics and hernia characteristics of girls with irreducible hernias (review question 6).

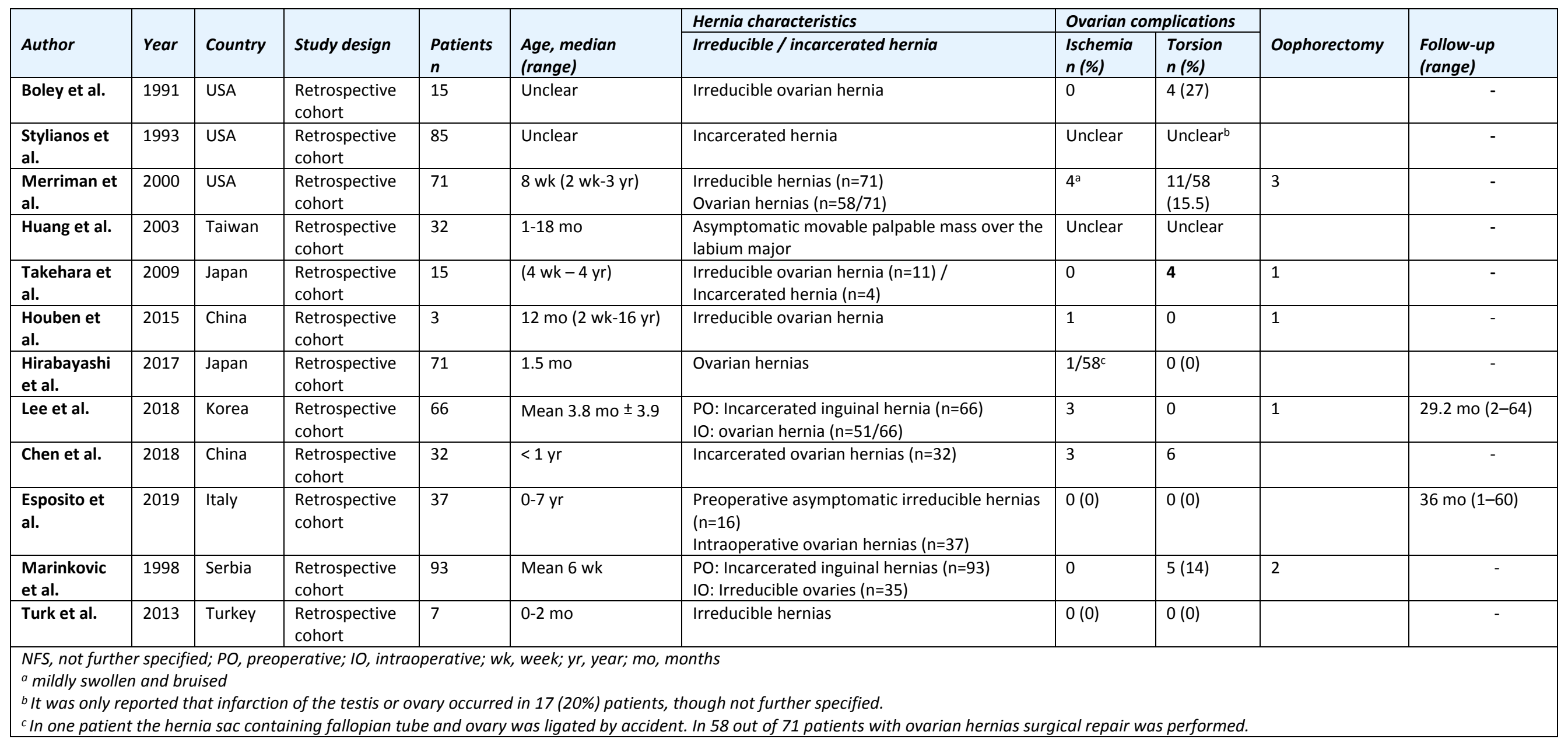


Meta-analysis of primary and secondary outcomes between laparoscopic and open hernia repair in children.

\subsection{A Perioperative complications}

\begin{tabular}{|c|c|c|c|c|c|c|c|c|c|c|}
\hline Study or Subgroup & $\begin{array}{r}\text { LH } \\
\text { Events }\end{array}$ & Total & $\begin{array}{r}\mathrm{OH} \\
\text { Events }\end{array}$ & Total & Weight & $\begin{array}{l}\text { Odds Ratio } \\
\text { M-H, Random, } 95 \% \mathrm{Cl}\end{array}$ & & $\begin{array}{r}\text { Odds } \\
\text { M-H, Rando }\end{array}$ & $\begin{array}{l}\text { Ratio } \\
\text { om, } 95 \% \mathrm{Cl}\end{array}$ & \\
\hline Celebi 2014 & 0 & 28 & 0 & 31 & & Not estimable & & & & \\
\hline Gause 2016 & 1 & 26 & 0 & 15 & $47.0 \%$ & $1.82[0.07,47.61]$ & & & & \\
\hline Saranga 2008 & 2 & 35 & 0 & 34 & $53.0 \%$ & $5.15[0.24,111.30]$ & & & & \\
\hline Shalaby 2012 & 0 & 125 & 0 & 125 & & Not estimable & & & & \\
\hline Total $(95 \% \mathrm{Cl})$ & & 214 & & 205 & $100.0 \%$ & $3.16[0.34,29.60]$ & & & & \\
\hline Total events & 3 & & 0 & & & & & & & \\
\hline \multicolumn{7}{|c|}{$\begin{array}{l}\text { Heterogeneity: } \text { Tau }^{2}=0.00 ; \mathrm{Chi}^{2}=0.21, \mathrm{df}=1(P=0.65) ;\left.\right|^{2}=0 \% \\
\text { Test for overall effect: } Z=1.01(P=0.31)\end{array}$} & 0.01 & $\begin{array}{l}0.1 \\
\text { Favours LH }\end{array}$ & Favours $\mathrm{OH}$ & 100 \\
\hline
\end{tabular}

\subsection{B Postoperative complications}

\begin{tabular}{|c|c|c|c|c|c|c|c|c|c|c|}
\hline Study or Subgroup & $\begin{array}{l}\text { LH } \\
\text { Events }\end{array}$ & Total & $\begin{array}{l}\mathrm{OH} \\
\text { Events }\end{array}$ & Total & Weight & $\begin{array}{l}\text { Odds Ratio } \\
\text { M-H, Random, } 95 \% \mathrm{Cl}\end{array}$ & & $\begin{array}{r}\text { Odds } \\
\text { M-H, Rando }\end{array}$ & $\begin{array}{l}\text { Ratio } \\
\text { om, } 95 \% \mathrm{Cl}\end{array}$ & \\
\hline Celebi 2014 & 3 & 28 & 0 & 31 & $11.6 \%$ & $8.65[0.43,175.22]$ & & & & $\longrightarrow$ \\
\hline Chan 2005 & 1 & 41 & 0 & 42 & $10.5 \%$ & $3.15[0.12,79.54]$ & & & & \\
\hline Gause 2016 & 0 & 26 & 1 & 15 & $10.4 \%$ & $0.18[0.01,4.77]$ & $\longleftarrow$ & & & \\
\hline Koivusalo 2008 & 0 & 47 & 0 & 42 & & Not estimable & & & & \\
\hline Saranga 2008 & 2 & 35 & 5 & 34 & $20.6 \%$ & $0.35[0.06,1.95]$ & & & & \\
\hline Shalaby 2012 & 3 & 87 & 12 & 92 & $24.5 \%$ & $0.24[0.06,0.88]$ & & & & \\
\hline Zhu 2015 & 2 & 53 & 19 & 49 & $22.4 \%$ & $0.06[0.01,0.28]$ & & & & \\
\hline Total $(95 \% \mathrm{Cl})$ & & 317 & & 305 & $100.0 \%$ & $0.37[0.10,1.32]$ & & & & \\
\hline Total events & 11 & & 37 & & & & & & & \\
\hline \multicolumn{7}{|c|}{$\begin{array}{l}\text { Heterogeneity: } \text { Tau }^{2}=1.28 ; \mathrm{Chi}^{2}=11.14, \mathrm{df}=5(\mathrm{P}=0.05) ;\left.\right|^{2}=55 \% \\
\text { Test for overall effect: } Z=1.53(P=0.13)\end{array}$} & 0.01 & Favours LH & Favours $\mathrm{OH}$ & 100 \\
\hline
\end{tabular}

\subsection{Recurrence rate}

LH OH Odds Ratio

Study or Subgroup Events Total Events Total Weight M-H, Random, $95 \% \mathrm{Cl}$

\begin{tabular}{lrrrrrr}
\hline Celebi 2014 & 0 & 28 & 0 & 31 & & Not estimable \\
Chan 2005 & 0 & 41 & 0 & 42 & & Not estimable \\
Gause 2016 & 1 & 26 & 0 & 15 & $20.6 \%$ & $1.82[0.07,47.61]$ \\
Koivusalo 2008 & 2 & 47 & 1 & 42 & $37.0 \%$ & $1.82[0.16,20.85]$ \\
Saranga 2008 & 0 & 35 & 0 & 34 & & Not estimable \\
Shalaby 2012 & 1 & 125 & 3 & 125 & $42.4 \%$ & $0.33[0.03,3.20]$ \\
Zhu 2015 & 0 & 53 & 0 & 49 & & Not estimable \\
Total (95\% Cl) & \multicolumn{7}{c}{355} & & 338 & $100.0 \%$ & $0.88[0.20,3.88]$ \\
Total events & 4 & & &
\end{tabular}

Test for overall effect: $Z=0.17(P=0.87)$

\subsection{Incidence of metachronous contralateral inguinal hernia (MClH)}

\begin{tabular}{|c|c|c|c|c|c|c|c|c|c|}
\hline Study or Subgroup & $\begin{array}{r}\text { LH } \\
\text { Events }\end{array}$ & Total & $\begin{array}{r}\mathrm{OH} \\
\text { Events }\end{array}$ & Total & Weight & $\begin{array}{l}\text { Odds Ratio } \\
\text { M-H, Random, } 95 \% \mathrm{Cl}\end{array}$ & $\begin{array}{r}\text { Odds } \\
\text { M-H, Rand } \\
\end{array}$ & $\begin{array}{l}\text { Ratio } \\
\text { om, } 95 \% \mathrm{Cl}\end{array}$ & \\
\hline Chan 2005 & 0 & 41 & 5 & 42 & $25.1 \%$ & $0.08[0.00,1.54]$ & $\longleftrightarrow$ & F & \\
\hline Koivusalo 2008 & 3 & 47 & 2 & 42 & $39.7 \%$ & $1.36[0.22,8.58]$ & & & \\
\hline Saranga 2008 & 0 & 35 & 0 & 34 & & Not estimable & & & \\
\hline Zhu 2015 & 1 & 53 & 7 & 49 & $35.1 \%$ & $0.12[0.01,0.98]$ & & & \\
\hline Total $(95 \% \mathrm{Cl})$ & & 176 & & 167 & $100.0 \%$ & $0.28[0.04,1.86]$ & & & \\
\hline Total events & 4 & & 14 & & & & & & \\
\hline \multicolumn{7}{|c|}{$\begin{array}{l}\text { Heterogeneity: } \operatorname{Tau}^{2}=1.45 ; \mathrm{Chi}^{2}=4.21, \mathrm{df}=2(\mathrm{P}=0.12) ; \mathrm{I}^{2}=52 \% \\
\text { Test for overall effect: } \mathrm{Z}=1.31(\mathrm{P}=0.19)\end{array}$} & 0.1 Favours LH & Favours $\mathrm{OH}$ & 100 \\
\hline
\end{tabular}


Meta-analysis of secondary outcomes between laparoscopic and open hernia repair in children (continued)

\subsection{A Unilateral operation time (in minutes)}

\begin{tabular}{|c|c|c|c|c|c|c|c|c|c|c|c|c|}
\hline \multirow[b]{2}{*}{ Study or Subgroup } & \multicolumn{3}{|c|}{ LH } & \multicolumn{3}{|c|}{$\mathrm{OH}$} & \multicolumn{2}{|r|}{ Mean Difference } & \multirow{2}{*}{\multicolumn{4}{|c|}{$\begin{array}{c}\text { Mean Difference } \\
\text { IV, Random, } 95 \% \mathrm{Cl}\end{array}$}} \\
\hline & Mean & SD & Total & Mean & SD & Total & Weight & IV, Random, $95 \% \mathrm{Cl}$ & & & & \\
\hline Chan 2005 & 23.25 & 6.26 & 40 & 18.38 & 5.71 & 40 & $16.0 \%$ & $4.87[2.24,7.50]$ & & & $\rightarrow$ & \\
\hline Gause 2016 & 27.9 & 15 & 17 & 53.2 & 30.4 & 10 & $6.2 \%$ & $-25.30[-45.45,-5.15]$ & & & & \\
\hline Inal 2013 & 28.85 & 8.14 & 20 & 20.53 & 7.42 & 20 & $15.0 \%$ & $8.32[3.49,13.15]$ & & & $\longrightarrow$ & \\
\hline Koivusalo 2008 & 35 & 11 & 47 & 18.25 & 6.75 & 42 & $15.6 \%$ & $16.75[13.00,20.50]$ & & & - & \\
\hline Saranga 2008 & 25.31 & 13.02 & 35 & 30.65 & 10.29 & 34 & $14.6 \%$ & $-5.34[-10.87,0.19]$ & & & & \\
\hline Shalaby 2012 & 7.6 & 3.5 & 25 & 12.8 & 4.5 & 28 & $16.2 \%$ & $-5.20[-7.36,-3.04]$ & & 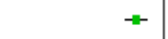 & & \\
\hline Zhu 2015 & 15.35 & 2.11 & 42 & 20.45 & 3.74 & 34 & $16.4 \%$ & $-5.10[-6.51,-3.69]$ & & 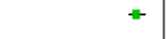 & & \\
\hline Total $(95 \% \mathrm{Cl})$ & & & 226 & & & 208 & $100.0 \%$ & $0.62[-5.70,6.95]$ & & & & \\
\hline $\begin{array}{l}\text { Heterogeneity: } \text { Tau }^{2}= \\
\text { Test for overall effect }\end{array}$ & $\begin{array}{l}63.22 \\
Z=0.19\end{array}$ & $\begin{array}{l}C h i^{2}=1 \\
(P=0 .\end{array}$ & $\begin{array}{l}72.99, d \\
85)\end{array}$ & $d f=6(P$ & $<0.000$ & $001) ; 1^{2}$ & $=97 \%$ & & $!_{-50}$ & $\begin{array}{l}-25 \\
\text { Favours LH }\end{array}$ & $\begin{array}{lr} & 25 \\
\text { Favours } \mathrm{OH}\end{array}$ & $\overrightarrow{50}$ \\
\hline
\end{tabular}

\subsection{B Bilateral operation time (in minutes)}

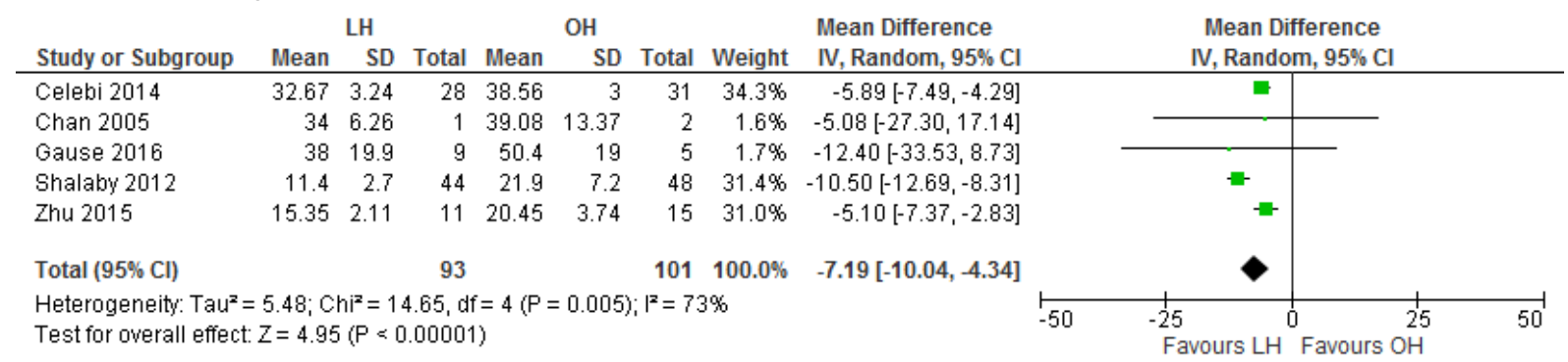

\subsection{Length of hospital stay (in hours)}

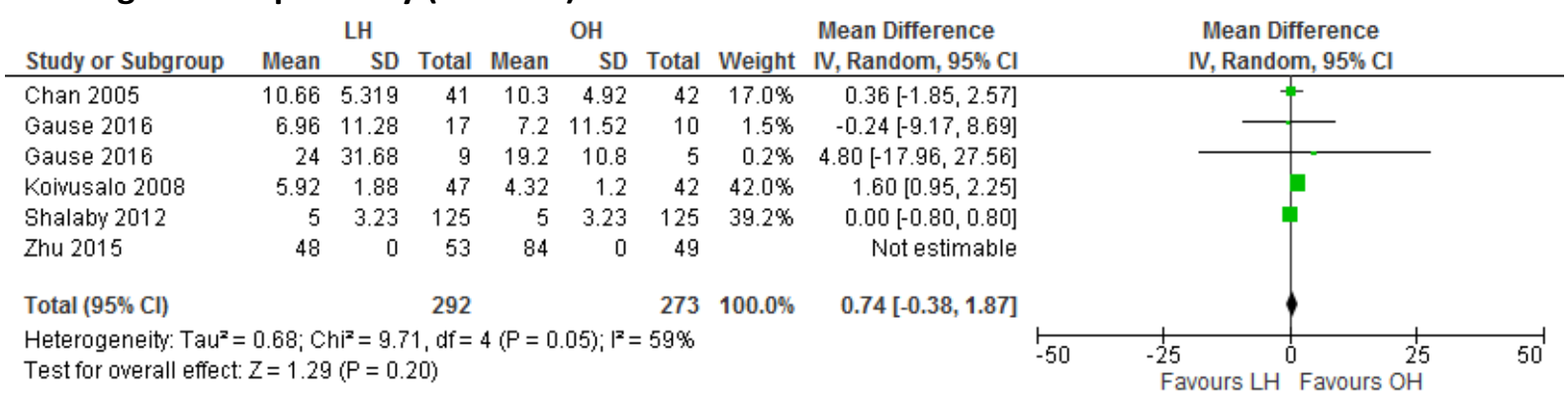

\subsection{Time to full recovery (in hours)}

\begin{tabular}{|c|c|c|c|c|c|c|c|c|c|c|c|c|}
\hline \multirow[b]{2}{*}{ Study or Subgroup } & \multicolumn{3}{|c|}{ LH } & \multicolumn{3}{|c|}{$\mathrm{OH}$} & \multicolumn{3}{|c|}{ Mean Difference } & \multirow{2}{*}{\multicolumn{2}{|c|}{$\begin{array}{c}\text { Mean Difference } \\
\text { IV, Random, } 95 \% \mathrm{Cl}\end{array}$}} & \\
\hline & Mean & SD & Total & Mean & SD & Total & Weight & IV, Random, $95 \% \mathrm{Cl}$ & & & & \\
\hline Celebi 2014 & 58.8 & 18 & 28 & 45.6 & 12 & 31 & $32.2 \%$ & $13.20[5.31,21.09]$ & & & - & \\
\hline Chan 2005 & 48.21 & 27.68 & 41 & 57.71 & 27.48 & 42 & $28.1 \%$ & $-9.50[-21.37,2.37]$ & & & & \\
\hline Gause 2016 & 60.96 & 33.36 & 17 & 78 & 78.72 & 10 & $5.6 \%$ & $-17.04[-68.34,34.26]$ & & & & \\
\hline Gause 2016 & 122.4 & 36 & 9 & 103.92 & 27.6 & 5 & $10.7 \%$ & $18.48[-15.26,52.22]$ & & & & \\
\hline Koivusalo 2008 & 57.6 & 33.6 & 47 & 60 & 43.2 & 42 & $23.4 \%$ & $-2.40[-18.62,13.82]$ & & & & \\
\hline Total $(95 \% \mathrm{Cl})$ & & & 142 & & & 130 & $100.0 \%$ & $2.05[-11.13,15.23]$ & & & & \\
\hline $\begin{array}{l}\text { Heterogeneity: Tau } \\
\text { Test for overall effec }\end{array}$ & $\begin{array}{l}124.35 \\
Z=0.30\end{array}$ & $\begin{array}{l}\mathrm{Chi}^{2}=1 \\
(\mathrm{P}=0.7\end{array}$ & $\begin{array}{l}\text { 12.00 } \\
76)\end{array}$ & $d f=4(P=$ & $=0.02) ;$ & $I^{2}=679$ & & & $!_{-100}$ & $\begin{array}{c}1 \\
-50 \\
\text { Favours LH }\end{array}$ & $\begin{array}{r}50 \\
\text { Favours } \mathrm{OH}\end{array}$ & 100 \\
\hline
\end{tabular}




\section{Question 2}

Meta-analysis of primary and secondary outcomes between the pre-peritoneal approach and trans-peritoneal approach for inguinal hernia repair in children.

\subsection{Recurrence rate}

EPA

Study or Subgroup Events Total Even

Bharathi 2008

Korkmaz 2018

Wang 2019

Total $(95 \% \mathrm{Cl})$

Total events

1412

8

548
Odds Ratio

TPA

$\begin{array}{rrrrr}7 & 112 & 2 & 51 & 65.6 \% \\ 0 & 24 & 2 & 47 & 17.9 \%\end{array}$

$47 \quad 17.9 \%$

$285 \quad 100.0 \%$

4

$187 \quad 16.5 \%$

$(P=0.70) ;\left.\right|^{2}=0 \%$

, Random, 95\% Cl Year

$1.63[0.33,8.15] 2008$

$0.37[0.02,8.05] 2018$

$1.37[0.06,33.71] 2019$

$1.22[0.33,4.47]$

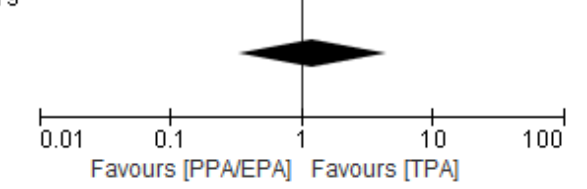

\subsection{A Unilateral operation time (in minutes)}

\begin{tabular}{|c|c|c|c|c|c|c|c|c|c|c|c|c|}
\hline \multirow[b]{2}{*}{ Study or Subgroup } & \multicolumn{3}{|c|}{ EPA } & \multicolumn{3}{|c|}{ TPA } & \multicolumn{3}{|c|}{ Mean Difference } & \multirow{2}{*}{\multicolumn{3}{|c|}{$\begin{array}{c}\text { Mean Difference } \\
\text { IV. Random, } 95 \% \mathrm{Cl}\end{array}$}} \\
\hline & Mean & SD & Total & Mean & SD & Total & Weight & IV. Random, $95 \% \mathrm{Cl}$ & Year & & & \\
\hline Bharathi 2008 & 15 & 3 & 101 & 25 & 7.5 & 45 & $33.8 \%$ & $-10.00[-12.27,-7.73]$ & 2008 & $\square$ & & \\
\hline Korkmaz 2018 & 18.41 & 6.05 & 22 & 35.12 & 10.8 & 42 & $31.1 \%$ & $-16.71[-20.84,-12.58]$ & 2018 & + & & \\
\hline Wang 2019 & 9.72 & 4.27 & 353 & 13.31 & 2.73 & 177 & $35.0 \%$ & $-3.59[-4.19,-2.99]$ & 2019 & $\square$ & & \\
\hline Total $(95 \% \mathrm{Cl})$ & & & 476 & & & 264 & $100.0 \%$ & $-9.84[-16.66,-3.03]$ & & & & \\
\hline \multicolumn{12}{|c|}{ 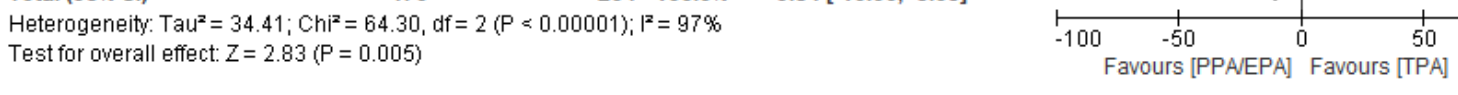 } & 100 \\
\hline
\end{tabular}

\subsection{B Bilateral operation time (in minutes)}

\begin{tabular}{|c|c|c|c|c|c|c|c|c|c|c|c|c|c|}
\hline \multirow[b]{2}{*}{ Study or Subgroup } & \multicolumn{3}{|c|}{ EPA } & \multicolumn{3}{|c|}{ TPA } & \multicolumn{3}{|c|}{ Mean Difference } & \multirow{2}{*}{\multicolumn{4}{|c|}{$\begin{array}{c}\text { Mean Difference } \\
\text { IV, Random, } 95 \% \mathrm{Cl}\end{array}$}} \\
\hline & Mean & SD & Total & Mean & SD & Total & Weight & IV, Random, $95 \% \mathrm{Cl}$ & Year & & & & \\
\hline Bharathi 2008 & 25 & 1.25 & 11 & 40 & 1.25 & 6 & $54.8 \%$ & $-15.00[-16.24,-13.76]$ & 2008 & & $\square$ & & \\
\hline Korkmaz 2018 & 32.5 & 3.54 & 2 & 42 & 5.7 & 5 & $10.9 \%$ & $-9.50[-16.50,-2.50]$ & 2018 & & $\rightarrow-$ & & \\
\hline Wang 2019 & 13 & 1.32 & 59 & 25.5 & 4.7 & 10 & $34.3 \%$ & $-12.50[-15.43,-9.57]$ & 2019 & & $=$ & & \\
\hline Total $(95 \% \mathrm{Cl})$ & & & 72 & & & 21 & $100.0 \%$ & $-13.54[-16.08,-11.01]$ & & & $\bullet$ & & \\
\hline $\begin{array}{l}\text { Heterogeneity: Tau² } \\
\text { Test for overall effect }\end{array}$ & $\begin{array}{l}2.66 ; \mathrm{Cr} \\
\mathrm{Z}=10.4\end{array}$ & $\begin{array}{l}h i^{2}=4 \\
15(P<\end{array}$ & $\begin{array}{l}37, \mathrm{df}= \\
0.0000\end{array}$ & 2(P= & $0.11) ;$ & $I^{2}=549$ & & & & -100 & $\begin{array}{l}1 \\
-50 \\
\text { purs [PPAVEPA] }\end{array}$ & $\begin{array}{lc}0 & 50 \\
\text { Favours } & \text { [TPA] }\end{array}$ & 100 \\
\hline
\end{tabular}

\subsection{Conversion rate to open surgery}

\section{EPA \\ TPA}

Study or Subg
Bharathi 2008
Korkmaz 2018

Wang 2019

Total $(95 \% \mathrm{Cl})$

Total events

Test for overall effect: $Z=0.91(P=0.36)$

$0 \quad 616$ 0

$2 \quad 0$

Odds Ratio M-H, Random, $95 \% \mathrm{Cl}$

$\begin{array}{lllll}1 & 112 & 0 & 51 & 50.3 \%\end{array}$

283

$381 \quad 100.0 \%$

$P=0.53) ; 1=0 \%$

Random, 95\% Cl Year

$1.39[0.06,34.60] 2008$

[0.24, 154.61] 2018

Not estimable 2019

$2.88[0.29,28.28]$

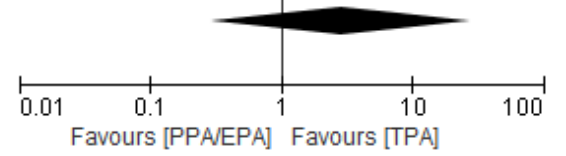


Meta-analysis of primary and secondary outcomes between the pre-peritoneal approach and trans-peritoneal approach for inguinal hernia repair in children (continued)

\subsection{A Intraoperative vessel injury}

\begin{tabular}{|c|c|c|c|c|c|c|c|c|c|c|c|}
\hline Study or Subgroup & $\begin{array}{l}\text { EPA } \\
\text { Events }\end{array}$ & Total & $\begin{array}{l}\text { TPA } \\
\text { Events }\end{array}$ & Total & Weight & $\begin{array}{c}\text { Odds Ratio } \\
\text { M-H, Random, } 95 \% \mathrm{Cl}\end{array}$ & Year & & $\begin{array}{r}\text { Odds } \\
\text { M-H, Rando }\end{array}$ & $\begin{array}{l}\text { Ratio } \\
\text { om, } 95 \% \mathrm{Cl}\end{array}$ & \\
\hline Bharathi 2008 & 2 & 146 & 2 & 67 & $41.4 \%$ & $0.45[0.06,3.27]$ & 2008 & & & & \\
\hline Korkmaz 2018 & 1 & 24 & 0 & 47 & $22.7 \%$ & $6.06[0.24,154.61]$ & 2018 & & & & \\
\hline Wang 2019 & 1 & 616 & 3 & 283 & $35.9 \%$ & $0.15[0.02,1.47]$ & 2019 & & & & \\
\hline Total $(95 \% \mathrm{Cl})$ & & 786 & & 397 & $100.0 \%$ & $0.55[0.09,3.38]$ & & & & & \\
\hline Total events & 4 & & 5 & & & & & & & & \\
\hline \multicolumn{8}{|c|}{$\begin{array}{l}\text { Heterogeneity: } \text { Tau }^{2}=1.05 ; \mathrm{Ch}^{2}=3.37, \mathrm{df}=2(\mathrm{P}=0.19) ; \mathrm{I}^{2}=41 \% \\
\text { Test for overall effect: } \mathrm{Z}=0.64(\mathrm{P}=0.52)\end{array}$} & 0.01 & $\begin{array}{ll}0.1 & 1 \\
\text { urs [PPAVEPA] }\end{array}$ & $\begin{array}{lc}1 & 10 \\
\text { Favours [TPA] }\end{array}$ & $100^{\circ}$ \\
\hline
\end{tabular}

\subsection{B Postoperative wound infection}

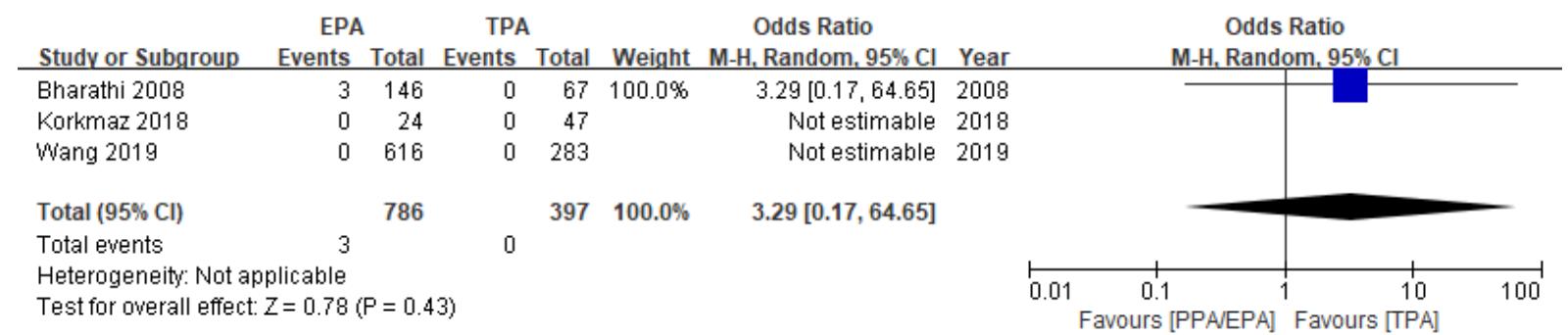

\subsection{Postoperative hydrocele}

EPA

TPA

Study or Subgroup Events Total Events

Bharathi 2008

Korkmaz 2018

Wang 2019

Total $(95 \% \mathrm{Cl})$

Total events

Heterogeneity: $\operatorname{Tau}^{2}=0.00 ; \mathrm{Chi}^{2}=1.37, \mathrm{df}=2(\mathrm{P}=0.50) ; \mathrm{I}^{2}=0 \%$

Test for overall effect: $Z=0.06(P=0.95)$

$\begin{array}{lllll}4 & 146 & 2 & 67 & 45.4 \%\end{array}$

$\begin{array}{lllll}1 & 24 & 0 & 47 & 12.8 \%\end{array}$

3616

$\begin{array}{rrr}0 & 47 & 12.8 \% \\ & 283 & 41.8 \%\end{array}$

\begin{abstract}
$397 \quad 100.0 \%$
\end{abstract} 4
Odds Ratio

$0.50) ; 1=0 \%$

H. Random, 95\% Cl Year $0.92[0.16,5.13] 2008$ $6.06[0.24,154.61] 2018$ $0.69[0.11,4.14] 2019$

\section{$1.04[0.32,3.30]$}

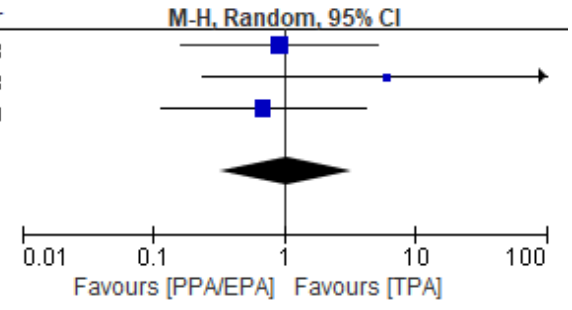

Odds Ratio M-H, Random, 95\% Cl

\subsection{Postoperative testicular atrophy}

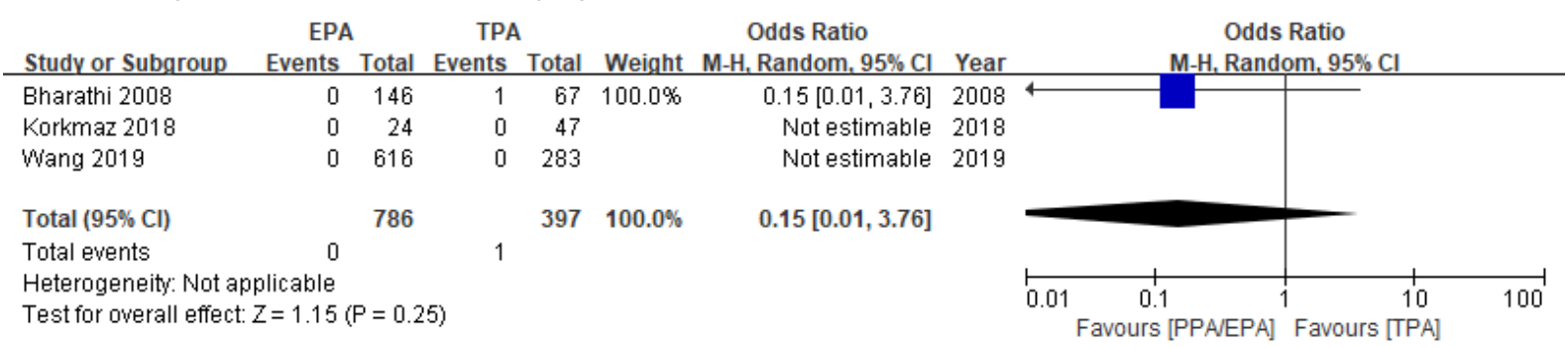




\section{Question 3}

A. Positive contralateral exploration rate (intervention group).

$\begin{array}{lrrr} & \text { Total } & \text { Positive CE (\%) } & 95 \% \text { Cl } \\ \text { Rothenberg 1955 } & 50 & 74,000 & 59,655 \text { to } 85,370 \\ \text { Clausen 1958 } & 164 & 48,171 & 40,314 \text { to } 56,095 \\ \text { McLaughlin 1960 } & 108 & 55,556 & 45,681 \text { to } 65,118 \\ \text { Gilbert 1958 } & 100 & 59,000 & 48,714 \text { to } 68,738 \\ \text { Laufer 1961 } & 120 & 63,333 & 54,050 \text { to } 71,942 \\ \text { Martin 1961 } & 55 & 83,636 & 71,197 \text { to } 92,234 \\ \text { Kling 1963 } & 33 & 66,667 & 48,173 \text { to } 82,039 \\ \text { Holcomb 1965 } & 433 & 55,889 & 51,070 \text { to } 60,627 \\ \text { Solomon 1967 } & 100 & 40,000 & 30,329 \text { to } 50,279 \\ \text { Gunnlaugsson 1967 } & 174 & 87,931 & 82,145 \text { to } 92,372 \\ \text { Simpson 1968 } & 218 & 86,239 & 80,941 \text { to } 90,519 \\ \text { Rowe 1969 } & 1965 & 48,142 & 45,912 \text { to } 50,379 \\ \text { Kalani 1972 } & 100 & 61,000 & 50,731 \text { to } 70,599 \\ \text { Wright 1982 } & 100 & 39,000 & 29,401 \text { to } 49,269 \\ \text { Rescorla 1984 } & 92 & 88,043 & 79,613 \text { to } 93,878 \\ \text { Tepas 1985 } & 121 & 61,983 & 52,713 \text { to } 70,652 \\ \text { Moss 1991 } & 300 & 85,000 & 80,448 \text { to } 88,844 \\ \text { Surana 1992 } & 390 & 48,974 & 43,909 \text { to } 54,055 \\ \text { Lugo Vincente 1995 } & 116 & 73,276 & 64,261 \text { to } 81,065 \\ \text { Jona (II) 1996 } & 331 & 55,287 & 49,753 \text { to } 60,726 \\ \text { Zampieri 2008 } & 118 & 47,458 & 38,191 \text { to } 56,855 \\ \text { Maillet 2014 } & 407 & 50,123 & 45,157 \text { to } 55,087 \\ \text { Disma 2018 } & 131 & 68,702 & 60,021 \text { to } 76,516 \\ \text { Total (fixed effects) } & 5726 & 57,680 & 56,390 \text { to } 58,961 \\ \text { Total (random effects) } & 5726 & 63,490 & 56,878 \text { to } 69,856\end{array}$

Heterogeneity: $Q=518,6745 ; d f=2(p<0.0001) ; 1^{2}=95.76 \%$

Proportion

$\mathrm{M}-\mathrm{H}$, Random, 95\% Cl

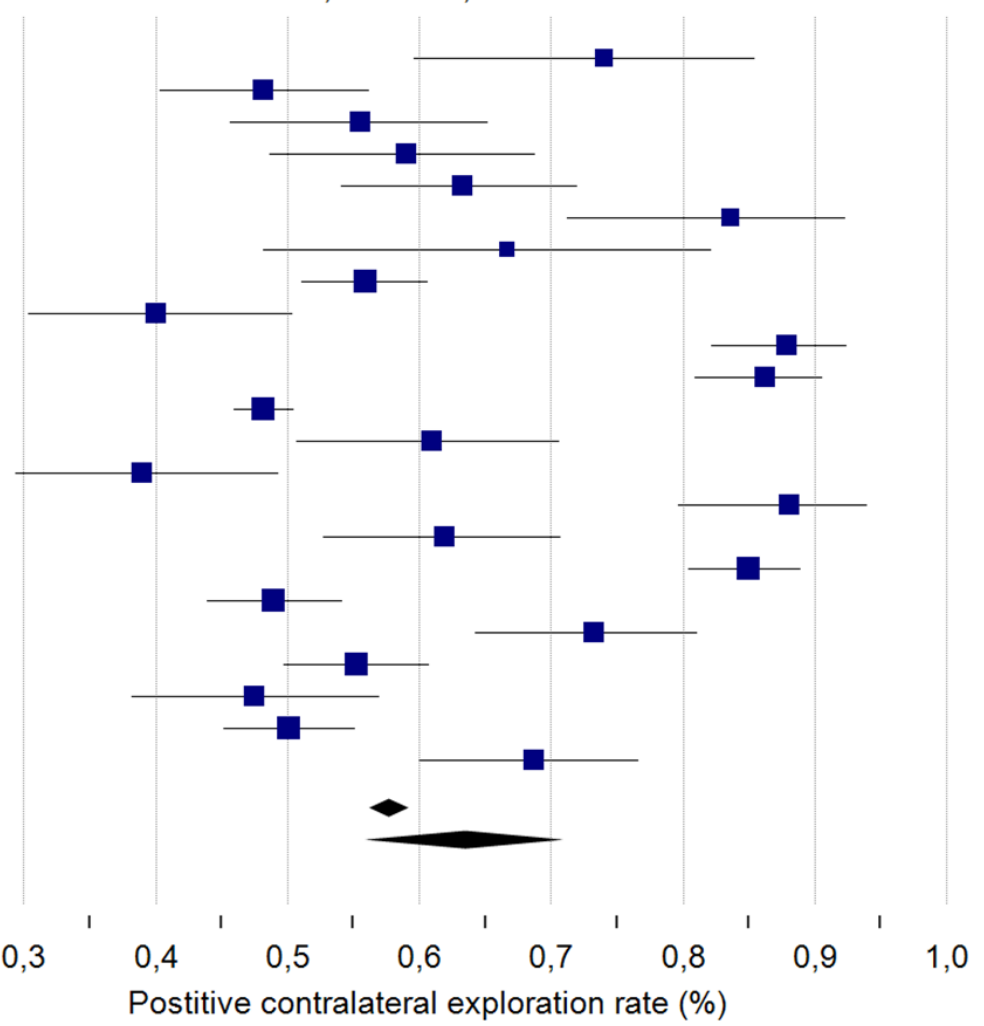




\section{B. Development of $\mathrm{MCIH}$ in control group.}

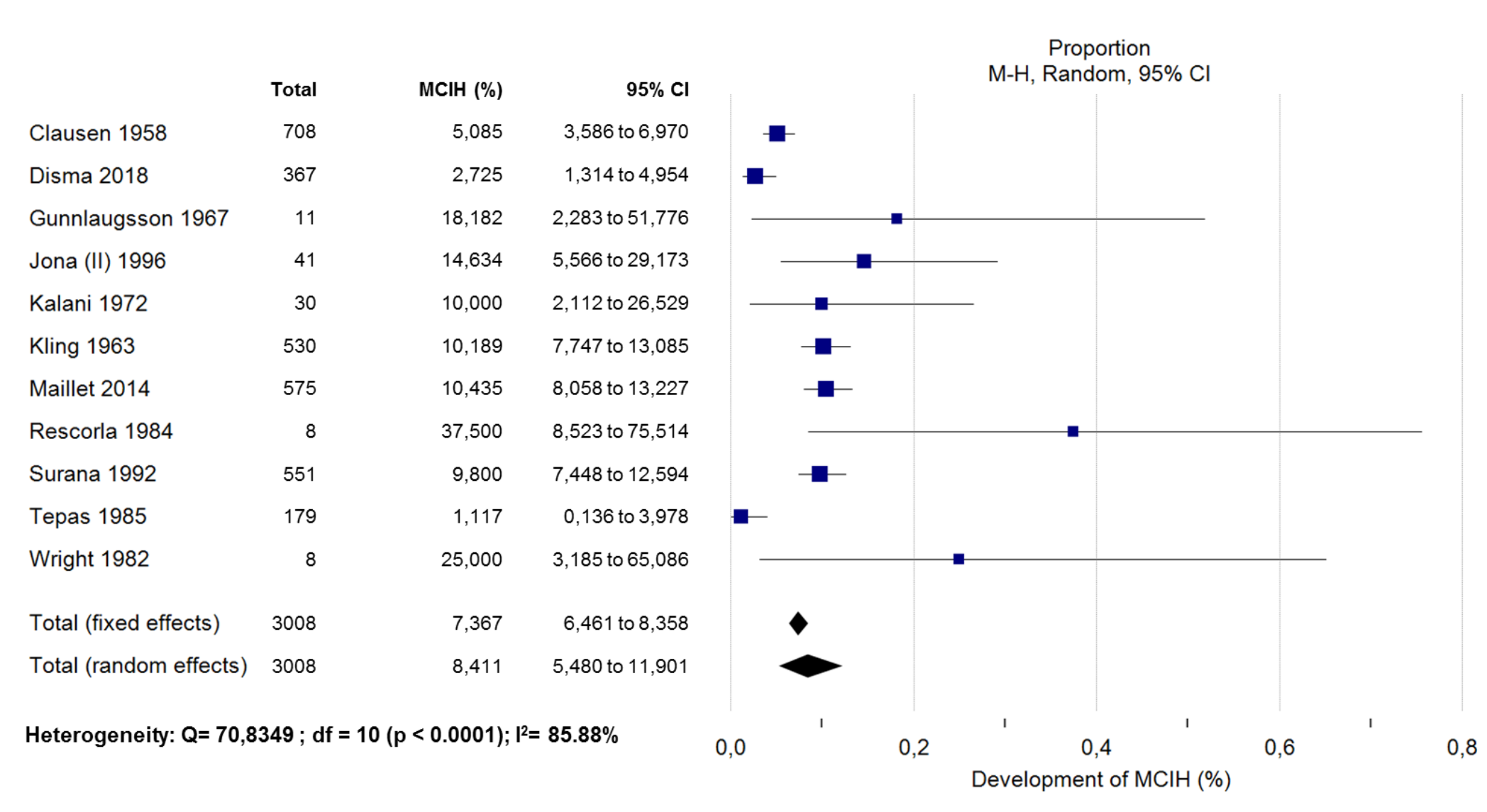




\section{Question 4}

Meta-analysis on primary and secondary outcomes between hernia repair before or after hospital discharge from the Neonatal Intensive Care Unit (NICU).

\subsection{Incarceration}

\begin{tabular}{|c|c|c|c|c|c|c|c|c|c|}
\hline Study or Subgroup & \multicolumn{2}{|c|}{ Early } & \multicolumn{2}{|l|}{ Late } & Weight & \multirow{2}{*}{$\begin{array}{c}\text { Odds Ratio } \\
\text { M-H, Random, 95\% Cl } \\
0.51[0.02,10.95]\end{array}$} & \multicolumn{2}{|c|}{$\begin{array}{c}\text { Odds Ratio } \\
\text { M-H, Random, } 95 \% \mathrm{Cl}\end{array}$} & \\
\hline Crankson 2015 & 0 & 23 & 2 & 61 & $2.6 \%$ & & & & \\
\hline Khan 2018 & 27 & 115 & 29 & 148 & $70.3 \%$ & $1.26[0.70,2.28]$ & - & & \\
\hline Lee 2011 & 5 & 45 & 0 & 35 & $2.9 \%$ & $9.64[0.51,180.56]$ & & & \\
\hline Pandey 2017 & 8 & 23 & 4 & 15 & $12.0 \%$ & $1.47[0.35,6.13]$ & & $=$ & \\
\hline Takahashi 2012 & 0 & 14 & 2 & 33 & $2.6 \%$ & $0.43[0.02,9.64]$ & & & \\
\hline Youn 2018 & 3 & 18 & 4 & 72 & $9.6 \%$ & $3.40[0.69,16.81]$ & & & \\
\hline Total (95\% Cl) & & 238 & & 364 & $100.0 \%$ & $1.42[0.87,2.34]$ & & & \\
\hline Total events & 43 & & 41 & & & & & & \\
\hline $\begin{array}{l}\text { Heterogeneity: } \operatorname{Tau}^{2}= \\
\text { Test for overall effect }\end{array}$ & $\begin{array}{l}0.00 ; \mathrm{Chi}^{2} \\
\mathrm{z}=1.39(\mathrm{~F}\end{array}$ & $\begin{array}{l}P=3.95 \\
P=0.1\end{array}$ & 6) $d f=5(P$ & $=0.5$ & 6); $I^{2}=0 \%$ & & $\begin{array}{l}0.1 \\
\text { Favours early }\end{array}$ & $\begin{array}{r}10 \\
\text { Favours late }\end{array}$ & 100 \\
\hline
\end{tabular}

\subsection{Recurrence}

\begin{tabular}{lrrrrrr} 
& \multicolumn{9}{c}{ Early } & \multicolumn{2}{c}{ Late } & Odds Ratio \\
Study or Subgroup & Events & Total & Events & Total & Weight & M-H, Random, 95\% Cl \\
\hline Crankson 2015 & 3 & 23 & 2 & 61 & $29.7 \%$ & $4.42[0.69,28.42]$ \\
Khan 2018 & 4 & 115 & 2 & 148 & $34.9 \%$ & $2.63[0.47,14.62]$ \\
Pandey 2017 & 2 & 23 & 0 & 12 & $10.6 \%$ & $2.91[0.13,65.53]$ \\
Takahashi 2012 & 0 & 14 & 0 & 33 & & Not estimable \\
Youn 2018 & 2 & 18 & 2 & 72 & $24.8 \%$ & $4.38[0.57,33.44]$ \\
Total (95\% Cl) & & 193 & & 326 & $100.0 \%$ & $3.52[1.28,9.70]$
\end{tabular}

Total events $\quad 11 \quad 6 \quad 6 \quad 0.97)^{2}=0 \%$

Heterog

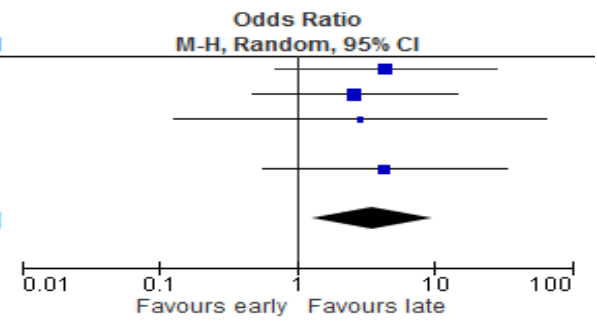

\subsection{Reoperation rate}

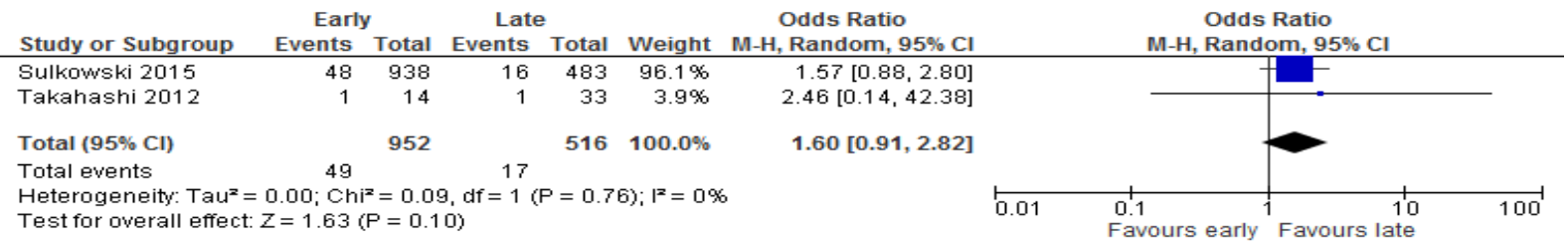

\subsection{Respiratory difficulties}

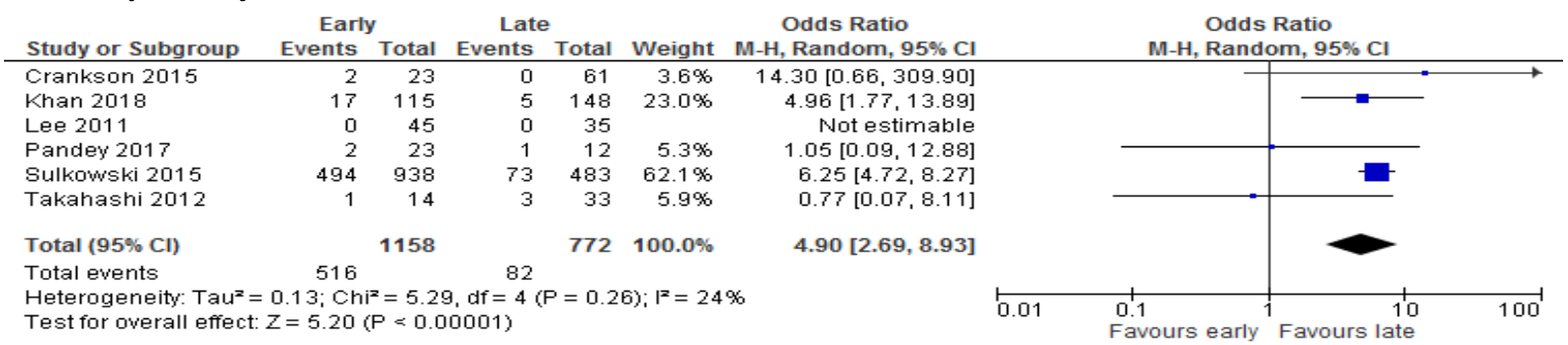




\section{Question 5}

Meta-analysis on the primary outcome between regional and general anesthesia in preterm infants.

5.1A. Postoperative apnea in preterm infants (overall)

\begin{tabular}{|c|c|c|c|c|c|c|c|c|c|c|c|}
\hline Study or Subgroup & \multicolumn{2}{|c|}{ Regional } & \multicolumn{2}{|c|}{ General } & \multicolumn{3}{|c|}{ Odds Ratio } & \multicolumn{4}{|c|}{$\begin{array}{c}\text { Odds Ratio } \\
\text { M-H, Random, } 95 \% \mathrm{Cl}\end{array}$} \\
\hline Welborn 1990 & 8 & 20 & 5 & 16 & $17.4 \%$ & $1.47[0.37,5.86]$ & 1990 & & & & \\
\hline Somri 1998 & 1 & 20 & 7 & 20 & $7.1 \%$ & $0.10[0.01,0.89]$ & 1998 & & & & \\
\hline Kunst 1999 & 4 & 8 & 4 & 9 & $9.5 \%$ & $1.25[0.19,8.44]$ & 1999 & & & & \\
\hline Williams 2001 & 2 & 10 & 2 & 14 & $7.5 \%$ & $1.50[0.17,12.94]$ & 2001 & & & & \\
\hline El Gohari 2004 & 9 & 15 & 12 & 15 & $12.8 \%$ & $0.38[0.07,1.92]$ & 2004 & & & & \\
\hline Das 2005 & 0 & 15 & 2 & 15 & $3.6 \%$ & $0.17[0.01,3.96]$ & 2005 & & & & \\
\hline GAS Study 2015-2019 & 10 & 198 & 14 & 196 & $42.1 \%$ & $0.69[0.30,1.60]$ & 2015 & & - & - & \\
\hline Total $(95 \% \mathrm{Cl})$ & & 286 & & 285 & $100.0 \%$ & $0.68[0.37,1.23]$ & & & & & \\
\hline Total events & 34 & & 46 & & & & & & & & \\
\hline $\begin{array}{l}\text { Heterogeneity: } \operatorname{Tau}^{2}=0 \\
\text { Test for overall effect: } Z\end{array}$ & $\begin{array}{l}.04 ; \mathrm{Chi}^{2} \\
=1.28(\mathrm{P}\end{array}$ & $\begin{array}{l}=6.36, \\
=0.2 C\end{array}$ & , df $=6$ & $(P=0.3$ & 38); $1^{2}=6$ & & & 0.01 & \begin{tabular}{c|}
0.1 \\
Favours Regional
\end{tabular} & 1 Favours Ge & $\begin{array}{l}10 \\
\text { General }\end{array}$ \\
\hline
\end{tabular}

5.1B. Postoperative apnea in preterm infants : "pure" regional anesthesia vs general anesthesia and sedation

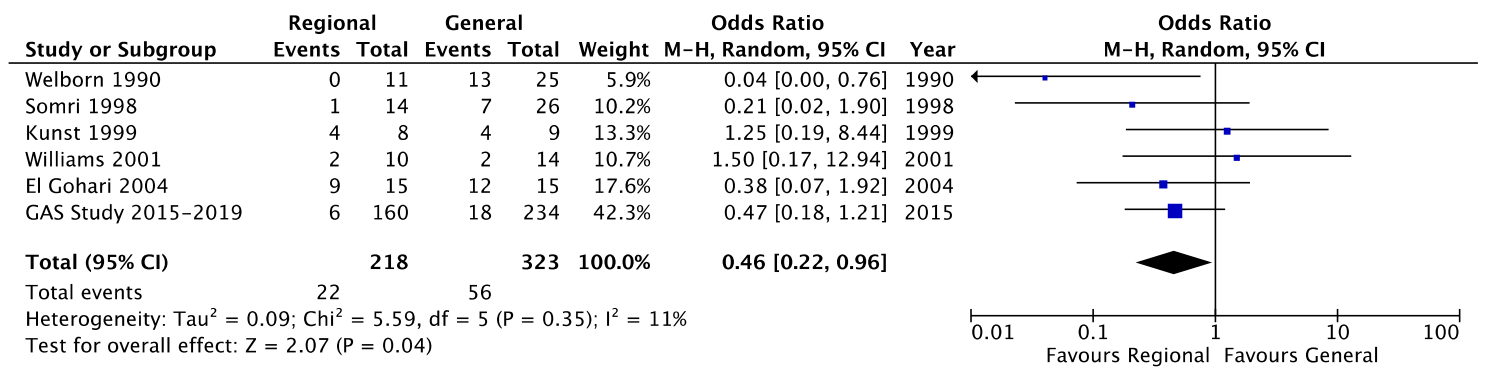

\subsection{Postoperative (early) apnea in preterm infants (within the first postoperative hour)}

\begin{tabular}{|c|c|c|c|c|c|c|c|c|c|c|c|}
\hline Study or Subgroup & \multicolumn{2}{|c|}{ Regional } & \multicolumn{2}{|c|}{ General } & \multicolumn{3}{|c|}{ Odds Ratio } & \multicolumn{4}{|c|}{$\begin{array}{l}\text { Odds Ratio } \\
\text { M-H, Random, } 95 \% \mathrm{Cl}\end{array}$} \\
\hline Kunst 1999 & 4 & 8 & 3 & 9 & $25.0 \%$ & $2.00[0.28,14.20]$ & 1999 & & & & \\
\hline Williams 2001 & 2 & 10 & 2 & 14 & $21.9 \%$ & $1.50[0.17,12.94]$ & 2001 & & & $=$ & \\
\hline Das 2005 & 0 & 15 & 2 & 15 & $12.2 \%$ & $0.17[0.01,3.96]$ & 2005 & $\leftarrow$ & & & \\
\hline GAS Study 2015-2019 & 3 & 198 & 11 & 196 & $40.9 \%$ & $0.26[0.07,0.94]$ & 2015 & & 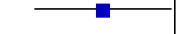 & & \\
\hline Total $(95 \% \mathrm{Cl})$ & & 231 & & 234 & $100.0 \%$ & $0.60[0.18,1.98]$ & & & & & \\
\hline Total events & 9 & & 18 & & & & & & & & \\
\hline $\begin{array}{l}\text { Heterogeneity: } \mathrm{Tau}^{2}= \\
\text { Test for overall effect: }\end{array}$ & $\begin{array}{l}.46 ; \mathrm{Chi}^{2} \\
=0.83(\end{array}$ & $\begin{array}{l}=4.35 \\
P=0.4\end{array}$ & , df $=3$ & $(P=0.2$ & 23); $1^{2}=3$ & & & 0.01 & $\begin{array}{cc}0.1 & 1 \\
\text { Favours Regional } & 1\end{array}$ & 1 Favours Ge & $\begin{array}{l}10 \\
\text { ieneral }\end{array}$ \\
\hline
\end{tabular}

\subsection{Postoperative apnea in preterm infants with pre-operative apnea episodes}

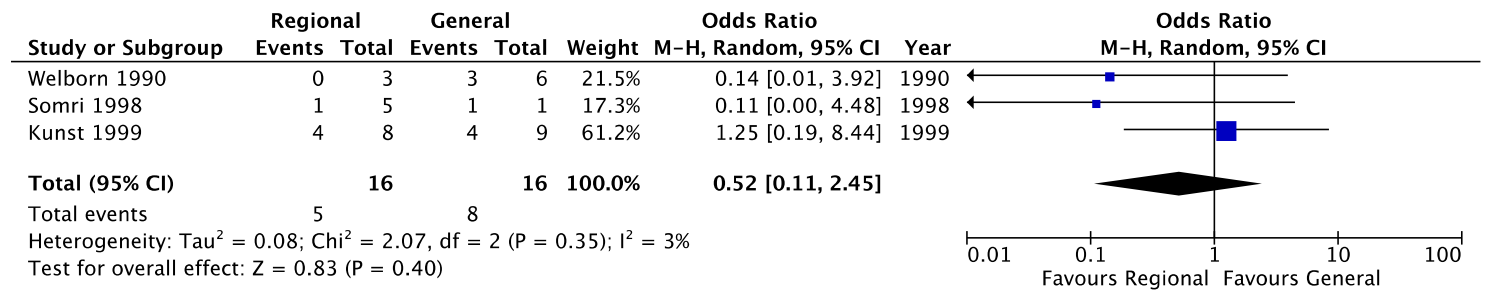

\subsection{E. Postoperative apnea requiring intervention (preterm infants)}

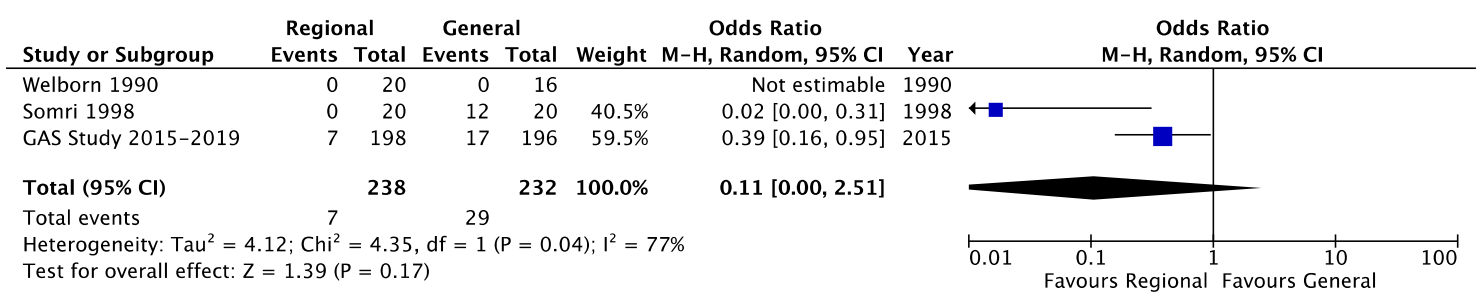


Meta-analysis on the secondary outcomes between regional and general anesthesia in preterm infants (continued)

\subsection{A. Postoperative bradycardia (preterm infants)}

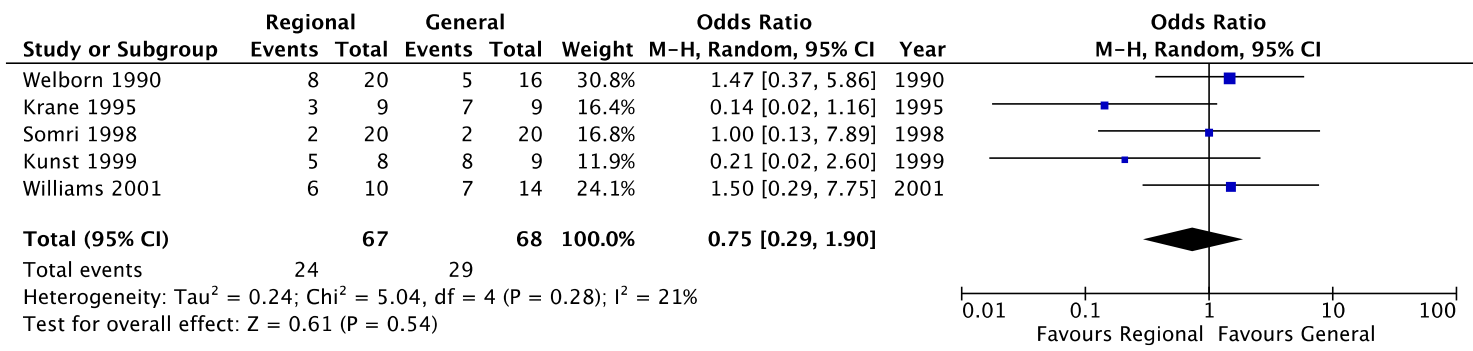

\subsection{B. Postoperative hypotension (preterm and term infants)}

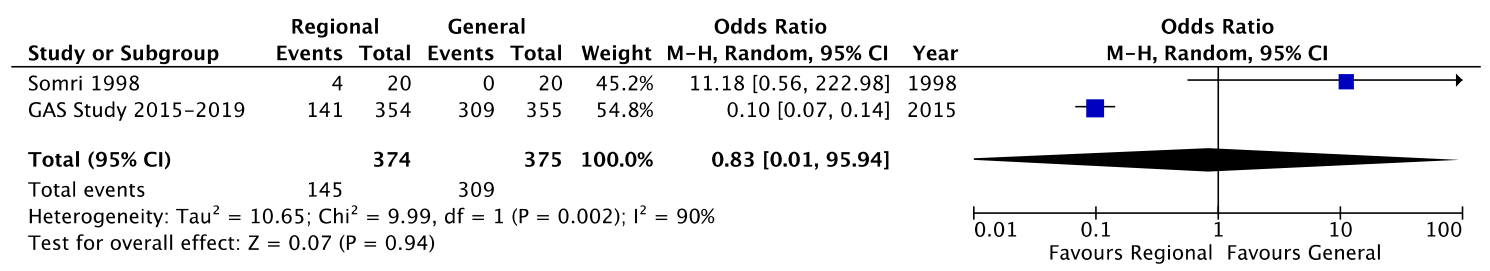

\subsection{Postoperative pain (preterm and term infants)}

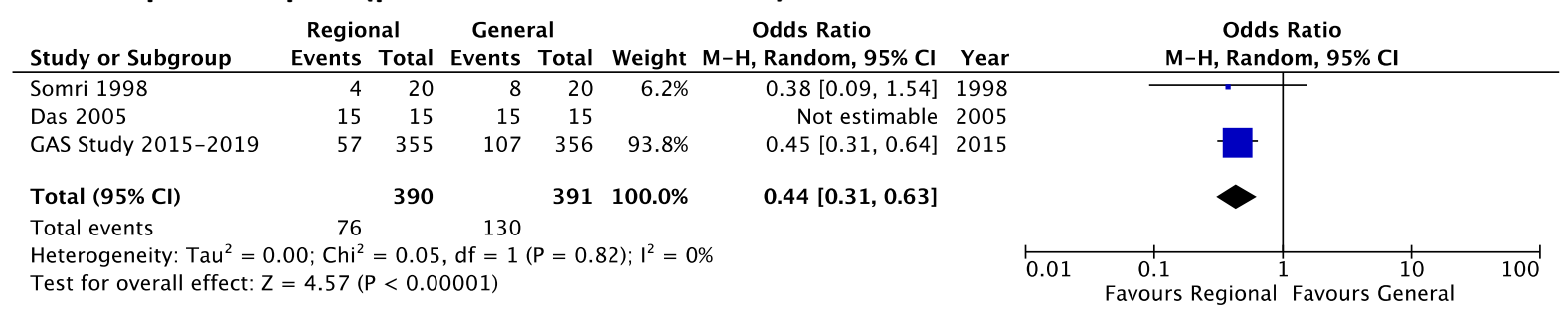

